\title{
Temporal and spectral dynamics underlying cognitive control modulated by task-irrelevant stimulus-response learning
}

\author{
Yanan $\mathrm{Cao}^{1} \cdot$ Xiangyi Cao ${ }^{1} \cdot$ Zhenzhu Yue $^{2} \cdot \operatorname{Ling}$ Wang $^{1}$
}

Published online: 17 October 2016

(C) Psychonomic Society, Inc. 2016

\begin{abstract}
Behavioral and recent neuroimaging findings have shown reversal of interference effects due to manipulating proportion congruency (PC), which suggests that taskirrelevant stimulus-response (S-R) associations are strengthened and applied to predict responses. However, it is unclear how the strengthened S-R associations are represented and applied in the brain. We investigated with a betweensubjects PC paradigm of the Hedge and Marsh task using electroencephalography (EEG). The behavioral results showed the reversal of the conflict effects, suggesting that task-irrelevant S-R associations were strengthened and used to prepare responses. The EEG results revealed the PC-related reversal of the conflict effects in the frontocentral N2 and parietal P3b amplitudes. Time-frequency analyses showed more pronounced PC-related reversal of the conflict effects in theta band $(4-8 \mathrm{~Hz})$ activity in frontocentral sites. These results suggest that the strengthened S-R associations due to PC manipulation modulated cognitive control. Importantly, the amplitude of lateralized readiness potential was higher in the high-PC condition than in the low-PC condition, suggesting that the strengthened short-term-memory spatial S-R associations that modulated cognitive control were applied similarly to long-term-memory spatial S-R associations.
\end{abstract}

Zhenzhu Yue

yuezhenzhu@gmail.com

$\triangle$ Ling Wang

lingwang@m.scnu.edu.cn

1 Center for Studies of Psychological Application and School of Psychology, Key Laboratory of Mental Health and Cognitive Science of Guangdong Province, South China Normal University, Guangzhou, China

2 Department of Psychology, Sun Yat-sen University, Guangzhou 510275, China
Keywords Cognitive control - Proportion congruency effect . Stimulus-response associations - Theta band activity · Lateralized readiness potential

The proportion congruency (PC) effect refers to the finding that interference effects, for example, the Simon (Simon, 1969), Stroop (MacLeod, 1991; Stroop, 1935), or Flanker (Eriksen \& Eriksen, 1974) effect, increase or decrease by increasing the ratio of the congruent or incongruent trials within a task. This paradigm has been widely employed to investigate cognitive control in laboratory studies (Bugg \& Crump, 2012). The interpretation of the PC effect is that top-down attentional control (Botvinick, Braver, Barch, Carter, \& Cohen, 2001) to relevant or irrelevant dimensions of a stimulus may be strategically adjusted. For example, in the mostly incongruent trial conditions, the irrelevant dimension is frequently detrimental to behavioral performance. Therefore, to reduce the influence of the irrelevant dimension, more attention is paid to the relevant dimension and less to the irrelevant dimension. As a result, the interference effect decreases. Functional magnetic resonance imaging (fMRI) studies have established that anterior midcingulate cortex (aMCC) and dorsolateral prefrontal cortex (DLPFC) are involved in detecting the need for control (e.g., by monitoring for the conflict in cognitive process; Botvinick et al., 2001) and implementing control (e.g., by biasing attention to relevant stimulus dimension; Egner \& Hirsch, 2005). Activity in these regions shows a similar pattern to the behavioral results of the PC effect (Carter et al., 2000), suggesting that these areas underlie the dynamic of cognitive control. Further studies show that the PC effect also appears when manipulating the ratio of congruent and incongruent trials according to contextual cues (Crump, Gong, \& Milliken, 2006) or specific items (Jacoby, Lindsay, $\&$ Hessels, 2003). For example, within a Stroop task, there are 
more incongruent trials when presenting stimuli in one location (low-PC cue), but more congruent trials when displaying stimuli in another location (high-PC cue). The Stroop effect decreases for the trials with low-PC cue and increases for the high-PC-cue-associated trials (Crump \& Milliken, 2009). These studies suggest that different strategies of top-down attention control may be triggered by stimulus information (i.e., context or item-specific control). These findings call for the development of computational models on cognitive control (Blais, Robidoux, Risko, \& Besner, 2007; Verguts \& Notebaert, 2008, 2009), in which top-down control is implemented at an item level. More recent fMRI studies have provided evidence supporting this idea. They show that the cognitive control system (aMCC and DLPFC) may operate at an item level (Blais \& Bunge, 2010), and the superior parietal lobule might represent the contextual information for implementing different control processes (King, Korb, \& Egner, 2012).

It has been shown that increasing the ratio of incongruent trials of a Simon task may even reverse the interference effect (i.e., slower reaction times [RT] in the congruent than in the incongruent trials; Hommel, 1994; Marble \& Proctor, 2000; Toth et al., 1995). The reversal of the interference effect is difficult to interpret by the attention modulation account mentioned. Increasing top-down control via biasing more attention to the relevant stimulus dimension and less to the irrelevant dimension may weaken the influence of the irrelevant stimulus dimension and therefore reduce the interference effect. However, even if enhancing top-down control may completely prevent the influence of the irrelevant stimulus dimension, the interference effect can reduce to zero at most, but is unable to be reversed. The reversal of the Simon effect rather suggests that the irrelevant spatially incompatible stimulus-response (S-R) associations are strengthened and applied to prepare responses, because these S-R associations may predict correct responses in most trials (Hommel, 1994). When the responses predicted by the PCmanipulation-strengthened incompatible S-R associations are different from the responses defined by task-relevant $\mathrm{S}$ $\mathrm{R}$ associations (note that this situation is the congruent condition), there is conflict between the response representations. A recent fMRI study supported this idea, showing that activity of aMCC and DLPFC also showed a reverse pattern associated with the reversal of the Simon effect (Xia, Li, \& Wang, 2016). This indicates that the cognitive control system was involved more in the congruent condition than in the incongruent condition, suggesting that the system monitored for the conflict induced by the PC manipulation strengthened S-R associations. This also implies that S-R learning may modulate cognitive control. However, it is unclear how S-R learning that modulates cognitive control is represented in the brain. We investigated this with the paradigm of PC effect and electroencephalography (EEG).
In this study, we employed a variant of the Simon task- the Hedge and Marsh (H\&M) task (Hedge \& Marsh, 1975). In a typical H\&M task (see Fig. 1), participants are required to discriminate the color (e.g., red or green) of a stimulus presented left or right of the fixation. The novel feature of the task is that the response buttons are also colored, one with the same color as the stimulus and the other with the alternate color. The task rule is either same-color (SC; pressing the key with the same color as the target) or alternate-color mapping (AC; pressing the key with the alternate color). The finding is that there is a positive Simon effect (faster RT when the locations of stimulus and response correspond than when they do not) in the SC rule but a negative Simon effect (slower RT when the locations correspond than when they do not) in the AC rule (De Jong, Liang, \& Lauber, 1994; Lu \& Proctor, 1994; Proctor \& Pick, 2003; Simon, Sly, \& Vilapakkam, 1981). The theoretical interpretation of the $\mathrm{H} \& \mathrm{M}$ effect is that the location of stimuli automatically activates its corresponding response in the $\mathrm{SC}$ rule, but the location of stimuli is recoded to activate its noncorresponding response in the AC rule (De Jong et al., 1994; Hedge \& Marsh, 1975; Wühr \& Biebl, 2009). In other words, the spatially compatible and incompatible S-R associations are used to predict responses in the $\mathrm{SC}$ and $\mathrm{AC}$ rules, respectively. There is conflict in cognitive processes when the response defined by relevant S-R associations is different from the response predicted by the spatially compatible (SC rule) or incompatible (AC rule) S-R associations, resulting in slower RT. This idea is supported by a recent fMRI study (Li, Xia, \& Wang, 2015), showing that in the H\&M task aMCC and DLPFC activity shows a positive Simon effect in the SC rule but a negative Simon effect in the AC rule, similar to the behavioral results.

The main aim of the study was to investigate how the PC manipulation strengthened S-R associations that may modulate cognitive control are represented and applied to predict responses. We carried out an EEG study manipulating the PC between subjects to answer this question. At the behavioral level, the reversal of the positive or negative Simon effect due to the PC manipulation would provide evidence that strengthened irrelevant S-R associations are used to predict responses. We hypothesized that increasing the ratio of incongruent trials may reverse the positive Simon effect in the SC rule, suggesting that spatially incompatible S-R associations are used to predict responses, which is similar to the results of previous studies (Hommel, 1994; Marble \& Proctor, 2000; Toth et al., 1995). The novel prediction by the H\&M task is that increasing the ratio of congruent trials may reverse the negative Simon effect in the AC rule (i.e., a positive Simon effect), because spatially compatible S-R associations are strengthened and used to predict responses. At the neural level, we hypothesized that the electrophysiological markers for cognitive control, for example, the N2 wave (van Veen \& Carter, 2002a; Yeung, Botvinick, \& Cohen, 2004) and theta band 




Fig. 1 The procedure of the experiments. The SC and AC color mapping rules were alternated between blocks. Con = congruent; Inc = incongruent. (Color figure online)

activity of time-frequency analysis (Cavanagh \& Frank, 2014) of the frontocentral sites, should show a reverse pattern similar to the behavioral results and recent fMRI findings (Xia et al., 2016). This would provide evidence that the strengthened S-R associations due to PC manipulation modulate cognitive control. Specifically, the N2 amplitude and theta band power might show stronger activity when the response defined by the relevant $\mathrm{S}-\mathrm{R}$ associations is different from that predicted by the strengthened S-R associations. More related to the main aim of the study, we hypothesized that the lateralized readiness potential (LRP) may be modulated by the PC. The LRP is the asymmetry of electrical potentials of the motor cortex between hemispheres when preparing a response (Coles, 1989; De Jong, Wierda, Mulder, \& Mulder, 1988; Gratton, Coles, Sirevaag, Eriksen, \& Donchin, 1988). The electrical potentials of the motor cortex contralateral to the response hand show larger negativity compared to the ipsilateral motor cortex. Thus, the time course of LRP between stimulus onset and response execution may reflect the processes for response activation. It has been shown that in the Simon task there is an initial "dip" (around 100-250 ms) in the LRP in the incongruent condition, which reflects the activation of the incorrect response predicted by the long-term-memory (LTM) spatially compatible S-R associations (De Jong et al., 1994; Leuthold, 2011; Valle-Inclán, 1996a, 1996b). If the PC-manipulationstrengthened short-term-memory (STM) spatial S-R associations are applied to predict responses in a way similar to the LTM spatial S-R association, LRP might also be influenced by PC manipulation. In the mostly incongruent condition, the irrelevant STM spatially incompatible S-R associations are strengthened and employed to predict responses. The spatially incompatible S-R associations might counteract the effect of the LTM spatially compatible S-R associations. As a result, the LRP deflection reflecting the response predicted by spatially compatible S-R associations may be reduced. In contrast, in the mostly congruent condition, the LRP deflection might be enhanced, because STM spatially compatible S-R associations are strengthened and used to predict responses. However, if the strengthened S-R associations due to PC manipulation function in a way that translates spatial codes of stimuli and responses (Vallesi, Mapelli, Schiff, Amodio, \& Umiltà 2005; Wiegand \& Wascher, 2005), the LRP may not be modulated by PC manipulation.

\section{Method}

\section{Participants}

Forty-eight healthy volunteers (mean age $\pm S D=21.0 \pm$ 1.7 years; 31 females) participated in the experiment. They were all right-handed, according to the Edinburgh Handedness Inventory (Oldfield, 1971), and had normal or corrected-to-normal vision. The participants were randomly divided into three groups, 16 participants in each group. All participants provided written informed consent and were paid for their participation. This study was approved by the local Ethics Committee of School of Psychology, South China Normal University.

\section{Apparatus and stimuli}

Participants were tested on a desktop computer with a 17-in. cathode ray tube (CRT) color monitor. Presentation software (Version 16.3, Neurobehavioral Systems Inc., USA) was used to program the task, present stimuli, and record behavioral responses in the experiment. The background of the visual display was black. A white crosshair presented $\left(2.9^{\circ} \times 2.9^{\circ}\right)$ in the screen's center served as a fixation point. The target stimulus was a square $\left(2.9^{\circ} \times 2.9^{\circ}\right)$ in red $(\mathrm{RGB}$ values: $255,0,0)$ or green (RGB: $0,255,0)$. The red and green squares were displayed above the fixation cross and on the left or right side of the screen (visual angle between the fixation cross and the stimulus: $9.0^{\circ}$ vertical $\times 10.5^{\circ}$ horizontal). Two rectangles $\left(1.5^{\circ}\right.$ vertical $\times 2.9^{\circ}$ horizontal; in red and green, respectively $)$ with a white line $\left(0.3^{\circ}\right.$ vertical $\times 4.4^{\circ}$ horizontal) below each were displayed at the bottom of the display and served as response labels. One was presented on the left and the other on the right side of the screen (visual angle between the fixation and the rectangle: $9.0^{\circ}$ vertical $\times$ $10.5^{\circ}$ horizontal) randomly from trial to trial. Responses were made by pressing the left Ctrl key (hereafter the left key) on a QWERTZ keyboard with the index finger of the left hand or 
the right Ctrl key (hereafter the right key) with the index finger of the right hand.

\section{Procedure}

Participants were assigned randomly to one of the three conditions based on the proportion of congruent to incongruent trials: $75 / 25,50 / 50$, and $25 / 75$. We manipulated the proportion congruency as a between-subjects factor, as there could be an asymmetrical shifting effect between mostly congruent and mostly incongruent sessions (Abrahamse, Duthoo, Notebaert, \& Risko, 2013). Each participant performed a red-green color discrimination task. The S-R color mapping rules ( $\mathrm{SC}$ and $\mathrm{AC}$ ) alternated across blocks. At the beginning of each block, a 5-s instruction showed subjects which colormapping rule should be employed in the upcoming block. After the instruction, we presented eight trials successively in each block (see Fig. 1). There were a total of 144 blocks (72 for each color mapping rule), resulting in a total of 1,152 trials. There were 864 congruent and 288 incongruent trials in the 75/25 group, 576 congruent and 576 incongruent trials in the 50/50 group, and 288 congruent and 864 incongruent trials in the $25 / 75$ group. The participants could take a break every 12 blocks in the experiment. On each trial, the fixation cross appeared alone for $400 \mathrm{~ms}$, followed by the response labels for $600 \mathrm{~ms}$. Subsequently, the target stimulus (a red or green square) was displayed and remained visible for $1,500 \mathrm{~ms}$ or until a response was made. In the latter case, the response was followed by a blank screen in black up to the end of the trial. Subjects had to respond to the stimulus as quickly and accurately as possible according to the current S-R color-mapping rule. The total duration of a trial was $2,500 \mathrm{~ms}$. The response labels indicated the color assignment of the response keys, which was varied pseudorandomly from trial to trial. For example, when the red response label was presented in the left side and the green label in the right side, in the SC rule participants had to press the "red" (i.e., left) key in response to the red stimulus but the "green" (i.e., right) key to the green stimulus. However, participants had to press the "green" key to the red stimulus and the "red" key to the green stimulus in the AC rule. Before the formal experiment, each participant completed a practice block consisting of 32 trials.

\section{Behavioral data analysis}

Incorrect trials and the correct response trials with RTs out of 3 standard deviations from the mean of each condition were excluded from further analysis. We then carried out a mixeddesign $3 \times 2 \times 2$ analysis of variance (ANOVA) with the between-subjects factor of Group (3 levels of proportions of congruent to incongruent trials: $75 / 25,50 / 50,25 / 75)$, and within-subjects factors of S-R Color Mapping (two levels:
SC rule, AC rule) and Spatial Congruency (two levels: Con, Inc) for both mean RTs and percentage errors (PEs).

\section{EEG recording and analysis}

EEG was continuously recorded from $64 \mathrm{Ag} / \mathrm{AgCl}$ electrodes mounted in an electrode cap using the Neuroscan system (Scan 4.5). The electrodes were placed according to the extended 10-20 system with an online left-mastoid reference. Vertical and horizontal electrooculogram (EOG) was recorded from electrodes placed above and below the left eye and the outer canthus of both eyes. Both EEG and EOG data were recorded at $1000-\mathrm{Hz}$ sampling rate with a $0.05-100-\mathrm{Hz}$ band pass using a Synamps digital amplifier system. Electrode impedance was kept below $10 \mathrm{k} \Omega$. All EEG data were analyzed using the EEGLAB toolbox (Version 11.0.5.4b). The data were first re-referenced to average reference, and then a 0.5 $35-\mathrm{Hz}$ band-pass filter was applied to the EEG signal. The correct response trials were segmented spanning $100 \mathrm{~ms}$ prior to stimulus onset to $1,000 \mathrm{~ms}$ after stimulus onset. Epochs were baseline corrected using a 100-ms window before stimulus onset, after visual inspection trials containing artifacts were removed. Blink artifacts were removed from the data using an independent component analyses (ICA) algorithm implemented in EEGLAB.

We analyzed the $\mathrm{N} 2$ and $\mathrm{P} 3 \mathrm{~b}$ components with the following procedure. The $\mathrm{N} 2$ was defined as the frontocentral negativity peaking approximately 200 $300 \mathrm{~ms}$ after stimulus onset. Previous researches have demonstrated that the $\mathrm{Cz}$ and $\mathrm{FCz}$ electrodes showed robust conflict effect in the N2 amplitude (van Veen \& Carter, 2002a; Yeung et al., 2004). The frontocentral areas were covered by the two electrodes and those around them (another seven electrodes, including $\mathrm{FC} 1$, $\mathrm{FC} 2, \mathrm{C} 1, \mathrm{C} 2, \mathrm{CP} 1, \mathrm{CPz}, \mathrm{CP} 2)$. The amplitudes for the $\mathrm{N} 2$ were extracted as the average of the time window 275-325 ms after stimulus onset, and then were averaged across the nine frontocentral electrodes sites. The P $3 b$ was a positive ERP deflection in parietal electrode sites peaking approximately $350-450 \mathrm{~ms}$ after stimulus onset, which showed robust Simon effect in the amplitude (Leuthold, 2011; Valle-Inclán, 1996a, 1996b). The parietal electrodes sites also consisted of nine electrodes, including $\mathrm{C} 1, \mathrm{Cz}, \mathrm{C} 2, \mathrm{P} 1, \mathrm{Pz}, \mathrm{P} 2, \mathrm{CP} 1, \mathrm{CPz}, \mathrm{CP} 2$. The amplitudes for the $\mathrm{P} 3 \mathrm{~b}$ were extracted as the average of the time window 375-425 ms after stimulus onset, and then were averaged across the nine parietal electrodes sites. The mixed-design ANOVA, similar to the behavior analysis, was performed on the averaged N2 and P3b amplitudes, respectively.

We calculated LRP for all correct response trials based the electrodes of $\mathrm{C} 3$ and $\mathrm{C} 4$. The formula is: mean $(\mathrm{C} 4-\mathrm{C} 3)_{\text {left-hand }}$ response + mean $\left.(\mathrm{C} 3-\mathrm{C} 4)_{\text {right-hand response }}\right] / 2$. Specifically, we 
subtracted the activity of the ipsilateral electrode from that of the contralateral electrode according to the response hand within each trial, and then averaged the difference wave between the two electrodes across trials. Initial positive LRP activation indicates an incorrect response induced by the stimulus location in the spatially incongruent condition (e.g., De Jong et al., 1994). The amplitudes for LRP were extracted as the average of the time window 150-175 ms after stimulus onset, chosen $25 \mathrm{~ms}$ with the peak time in the middle. We carried out a mixed-design ANOVA with factors Group and Color Mapping for the averaged LRP amplitude of incongruent trials.

\section{Time-frequency analysis}

Epochs were adjusted to start $750 \mathrm{~ms}$ before and end $1,500 \mathrm{~ms}$ after stimulus onset in order to have sufficient data for the analysis. Event-related spectral power (ERSP) was calculated on all epochs of the frontocentral sites (the same electrodes as in the $\mathrm{N} 2$ component analysis). The data in each epoch was convolved with a set of discrete complex Morlet wavelets, which were defined as a Gaussian-windowed complex sine wave: $A e^{-t^{2} /\left(2 \sigma^{2}\right)} e^{2 \pi f t i}$. In the formula, $f$ is the frequency, which increased from 4 to $8 \mathrm{~Hz}$ linearly, as this study focused on the theta band conflict-related processing (Cavanagh \& Frank, 2014). In the formula, $\sigma$ defines the width of the Gaussian window, which equals cycle $/ 2 \pi \mathrm{f}$, where cycle was set to 3 for all frequencies, considering the trade-off between temporal and frequency resolution. $A$ is amplitude, which equals $1 / \sqrt{\sigma \sqrt{\pi}}$, and $t$ is time. The power of the convolved epoch data was calculated as the sum of the square of the real part and the square of the imaginary part of the data. The power data were then baseline corrected by dividing the average power of the time window $(332 \mathrm{~ms}$ before stimulus onset to the stimulus onset). Finally, the power data were converted to a decibel $(\mathrm{dB})$ scale, $10 \times$ $\log 10(\operatorname{power}(\mathrm{t}))$. The theta band activity was the average activity of 4-8 Hz. They were extracted as the average of the time window 300-600 ms after stimulus onset, because both previous studies and this study revealed conflict-related theta band activity in a relatively large time window (e.g., Nigbur, Ivanova, \& Stürmer, 2011) and then were averaged across the nine frontocentral electrode sites. A mixed-design ANOVA, similar to the behavior analysis, was performed on the theta band activity.

Post hoc $t$ tests for the analyses of N2, P3b, LRP, and theta band were corrected for multiple comparisons using the false discovery rate (FDR; Benjamini, Krieger, \& Yekutieli, Benjamini et al. 2006), based on the Mass Univariate Toolbox for ERP analyses (http://openwetware. org/wiki/Mass_Univariate_ERP_Toolbox), written by Groppe, Urbach, and Kutas (2011).

\section{Results}

\section{Behavioral results}

As illustrated in Fig. 2a, the mixed-design ANOVA for RTs revealed that the main effect of Group was significant, $F(2,45)$ $=3.39, p=.043, \eta_{\mathrm{p}}{ }^{2}=.131$, indicating that RTs of the $25 / 75$ group $(535 \mathrm{~ms})$ were slower than those of the 50/50 (482 ms) and 75/25 (493 ms) groups. There was a significant main effect of Color Mapping effect, $F(1,45)=595.64, p<.001, \eta_{\mathrm{p}}{ }^{2}=.930$, showing that responses under the $\mathrm{SC}$ rule $(463 \mathrm{~ms})$ were faster than those under the $\mathrm{AC}$ rule $(544 \mathrm{~ms})$. The main effect of Congruency was also significant, $F(1,45)=6.30, p=.016$, $\eta_{\mathrm{p}}{ }^{2}=.123$. The three-way interaction of Group $\times$ Color Mapping $\times$ Congruency was not significant, $F(2,45)=0.03, p$ $=.970, \mathrm{y}_{\mathrm{p}}{ }^{2}=.001$. However, there was a significant interaction between Color Mapping and Congruency, $F(1,45)=69.64, p<$ $.001, \mathrm{y}_{\mathrm{p}}^{2}=.607$, indicating that RTs were faster in the congruent condition (454 ms) than in the incongruent condition $(471 \mathrm{~ms})$ in the SC rule, but slower (564 ms vs. $524 \mathrm{~ms}$ ) in the AC rule. The interaction between Group and Congruency was also significant, $F(2,45)=55.79, p<.001, \mathrm{y}_{\mathrm{p}}^{2}=.713$, showing that RTs were faster in the congruent condition (469 ms) than in the incongruent condition (516 ms) in the $75 / 25$ group, but slower ( $570 \mathrm{~ms}$ vs. $501 \mathrm{~ms}$ ) in the 25/75 group, which indicates the PC effect. Interaction between Group and Color Mapping was not significant, $F(2,45)=0.61, p=.547, \mathrm{y}_{\mathrm{p}}^{2}=.026$, showing that the difference between the $\mathrm{SC}$ and $\mathrm{AC}$ rules was similar across groups. To analyze the PC effect in more detail, we compared the Simon effect under each mapping rule across groups (see Fig. 2c). The positive Simon effect under the SC rule was significantly increased by increasing the ratio of congruent trials (75/25 group: $77 \mathrm{~ms}), t(30)=5.92, p<.001, d=2.092$, but decreased and even reversed by increasing the ratio of incongruent trials ( $25 / 75$ group: $-41 \mathrm{~ms}), t(30)=4.05, p<.001, d=1.433$, compared to the 50/50 group (16 ms). In contrast, the negative Simon effect under the AC rule was significantly reduced and even reversed in the 75/25 group (17 ms), $t(30)=5.15, p<.001$, $d=1.820$, but increased in the $25 / 75$ group $(-97 \mathrm{~ms}), t(30)=$ $3.92, p<.001, d=1.386$, compared to the $50 / 50$ group $(-40 \mathrm{~ms})$.

For PEs, a similar pattern as in RTs was observed (see Fig. 2b). A significant main effect of Color Mapping appeared, $F(1,45)=31.28, p<.001, \eta_{\mathrm{p}}{ }^{2}=.410$, showing that there were more errors in the AC rule (7.1\%) than in the SC rule $(4.7 \%)$. The main effect of Congruency was also significant, $F(1,45)=6.93, p=.012, \eta_{\mathrm{p}}{ }^{2}=.133$. However, the main effect of Group was not significant, $F(2,45)=1.52, p=.229$, $\eta_{\mathrm{p}}{ }^{2}=.063$. The three-way interaction of Group $\times$ Color Mapping $\times$ Congruency was significant, $F(2,45)=3.51, p=$ $.038, \mathrm{yp}_{\mathrm{p}}^{2}=.135$, indicating that the congruency effect varied according to both Group and Color Mapping. In addition, there was a significant interaction between Color Mapping and Congruency, $F(1,45)=44.45, p<.001, \mathrm{y}_{\mathrm{p}}{ }^{2}=.497$, 
a

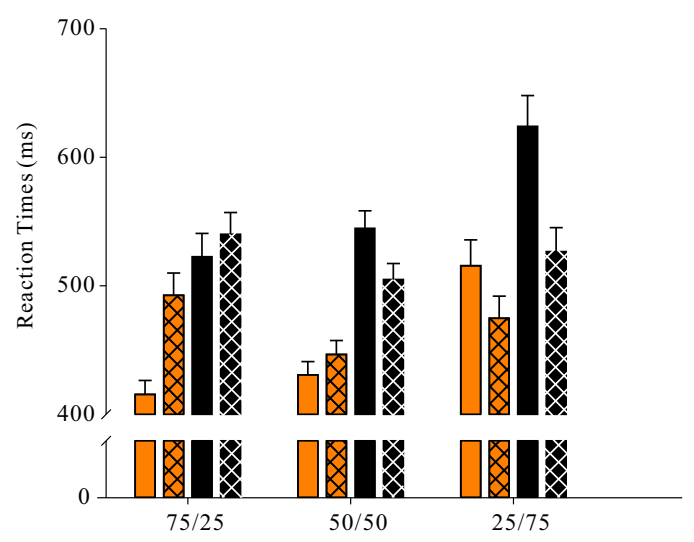

$\mathrm{c}$

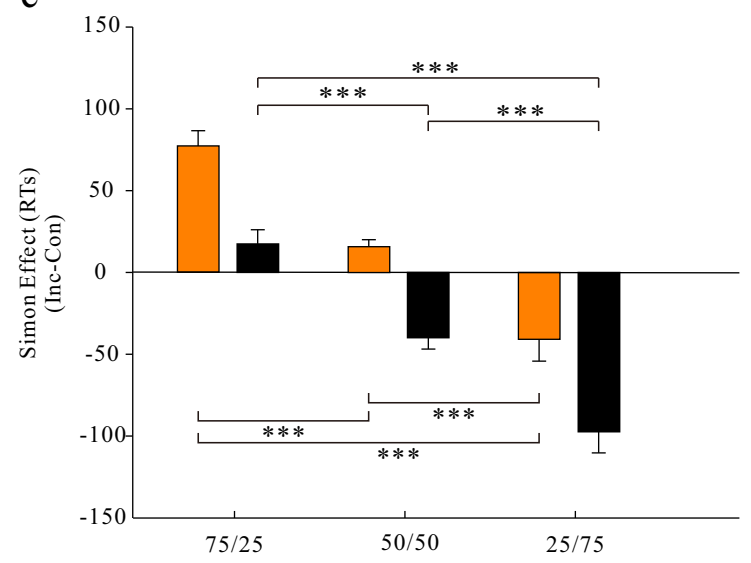

Fig. 2 The behavioral results. (a) Reaction times (RTs). (b) Percentage of errors (PEs). (c) Simon effect (in RTs): incongruent minus congruent condition. (d) Simon effect (in PEs): incongruent minus congruent condition. The data were grouped according to PC, which is shown by

indicating that PEs were less in the congruent condition (4.1\%) than in the incongruent condition (5.3\%) in the SC rule, but more $(9.2 \%$ vs. $5.0 \%)$ in the AC rule. The interaction between Group and Congruency was also significant, $F(2,45)=25.36, p<.001, \mathrm{y}_{\mathrm{p}}{ }^{2}=.530$, showing that PEs were less in the congruent condition (2.9\%) than in the incongruent condition $(6.3 \%)$ in the $75 / 25$ group, but more $(10.4 \%$ vs. $3.9 \%$ ) in the $25 / 75$ group. Interaction between Group and Color Mapping was not significant, $F(2,45)=1.80, p=$ $.177, \mathrm{y}_{\mathrm{p}}^{2}=.074$, showing that the difference between the SC and AC rules was similar across groups. To analyze the PC effect in more detail, we compared the Simon effect for PEs under each mapping rule across groups (see Fig. 2d). The positive Simon effect under the SC rule was significantly increased by increasing the ratio of congruent trials $(75 / 25$ group: $4.7 \%), t(30)=2.62, p=.014, d=.927$, but decreased and even reversed by increasing the ratio of incongruent trials $(25 / 75$ group: $-2.3 \%), t(30)=3.43, p=.002, d=1.211$, compared to the $50 / 50$ group $(1.4 \%)$. In contrast, the negative Simon effect under the AC rule was significantly reduced and b

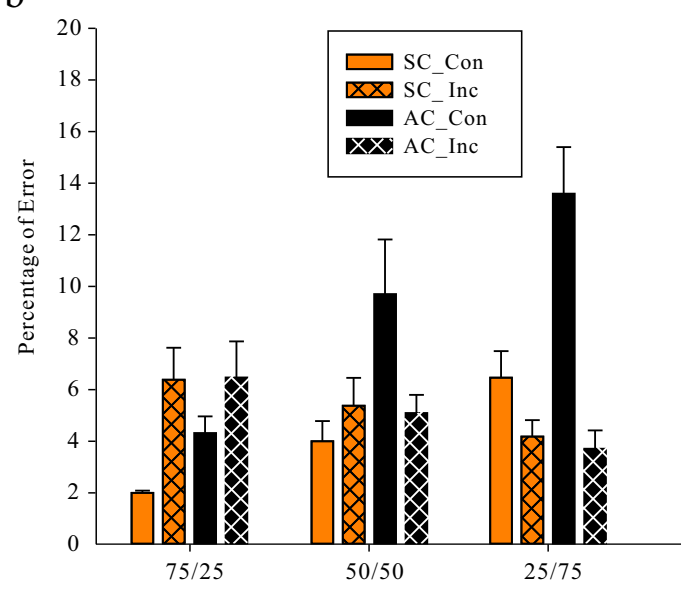

d

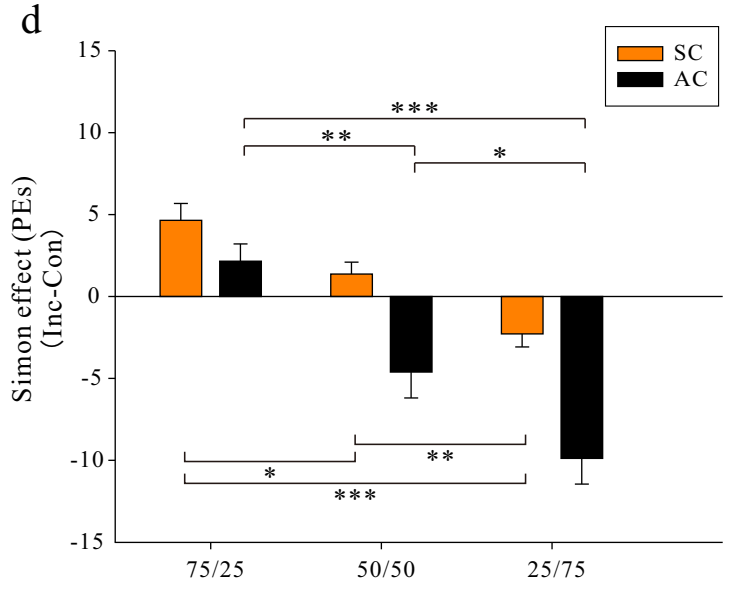

the way of con/inc (e.g., 75/25 means that there were $75 \%$ congruent trials and $25 \%$ incongruent trials). Error bars indicate standard errors. SC $=$ same-color rule , Con $=$ congruent Inc $=$ incongruent AC $=$ alternatecolor rule. (Color figure online). $* p<.05 . * * p<.01 . * * * p<001$

even reversed in the 75/25 group (2.2\%), $t(30)=3.57, p=$ $.001, d=1.262$, but increased in the $25 / 75$ group $(-9.9 \%)$, $t(30)=2.37, p=.024, d=.838$, compared to the $50 / 50$ group $(-4.6 \%)$.

In summary, the key findings were that, in both RTs and PEs, the negative Simon effect in the AC rule was reversed in the $75 / 25$ group by increasing the ratio of congruent trials compared with that of the 50/50 group, and the positive Simon effect in the SC rule was reversed in the $25 / 75$ group by increasing the ratio of incongruent trials compared with that of the 50/50 group.

\section{Electrophysiological results}

N2 wave

If the strengthened S-R associations due to PC manipulation modulated cognitive control, the electrophysiological markers for cognitive control, for example, the N2 component of frontocentral sites, should show a reverse pattern 
similar to the behavioral results. Here, we report the results of a typical $\mathrm{N} 2$ electrode, $\mathrm{Cz}$, where previous studies revealed conflict effects (van Veen \& Carter, 2002b; Yeung et al., 2004). The ANOVA on the $\mathrm{N} 2$ amplitude at the $\mathrm{Cz}$ electrode in the 275-325 ms time window (see Fig. 3a) revealed a significant main effect of Color Mapping, $F(1,45)=$ 107.63, $p<.001, \eta_{\mathrm{p}}{ }^{2}=.705$, indicating that the amplitude in the $\mathrm{SC}$ rule $(-0.00 \mu \mathrm{V})$ was smaller than that in the AC rule $(-1.25 \mu \mathrm{V})$. The main effect of Congruency was also significant, $F(1,45)=9.70, p=.003, \eta_{\mathrm{p}}^{2}=.177$, indicating that the incongruent trials $(-0.75 \mu \mathrm{V})$ elicited a larger N2 amplitude than the congruent trials $(-0.50 \mu \mathrm{V})$. The main effect of Group was not significant, $F(1,45)=.019, p=.982, \eta_{\mathrm{p}}^{2}=$ .001 . However, there was a significant three-way interaction of Group $\times$ Color Mapping $\times$ Congruency, $F(2,45)=4.73, p$
$=.014, \eta_{\mathrm{p}}{ }^{2}=.174$, indicating that the congruency effect varied according to both Group and Color Mapping. In addition, there was a significant two-way interaction of Group $x$ Congruency, $F(2,45)=12.65, p<.001, \eta_{\mathrm{p}}^{2}=.360$, showing that the $\mathrm{N} 2$ amplitude was smaller in the congruent condition $(-0.23 \mu \mathrm{V})$ than in the incongruent condition $(-1.03 \mu \mathrm{V})$ in the $75 / 25$ group, but larger $(-0.64 \mu \mathrm{V}$ vs. $-0.49 \mu \mathrm{V})$ in the $25 /$ 75 group. This indicates the PC effect. There was also a significant interaction between Color Mapping and Congruency, $F(1,45)=8.91, p=.005, \mathrm{y}_{\mathrm{p}}^{2}=.165$, indicating that the $\mathrm{N} 2$ amplitude was smaller in the congruent condition $(0.22 \mu \mathrm{V})$ than in the incongruent condition $(-0.22 \mu \mathrm{V})$ in the $\mathrm{SC}$ rule, while congruent trials $(-1.22 \mu \mathrm{V})$ elicited $\mathrm{N} 2$ amplitude similar to incongruent trials $(-1.27 \mu \mathrm{V})$ in the AC rule. Interaction between Group and Color Mapping was not
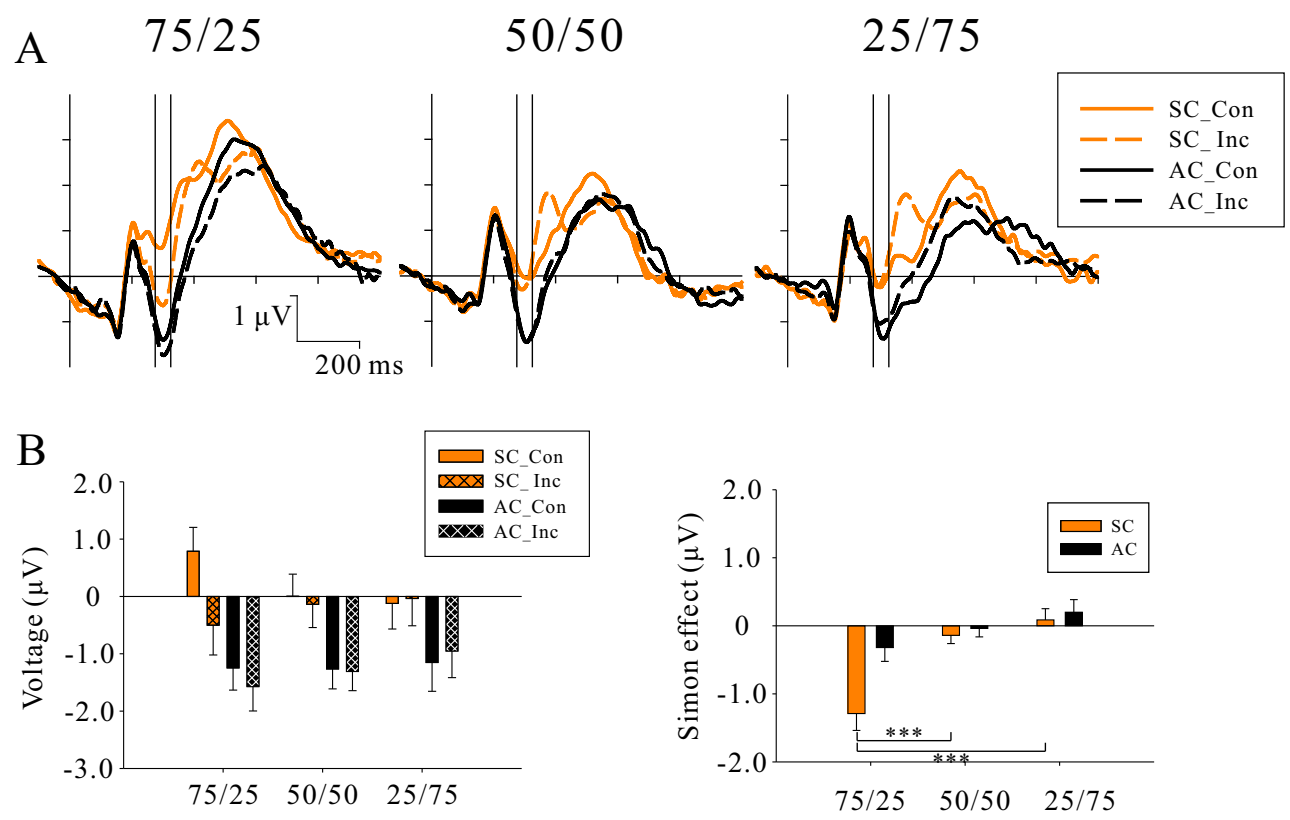

$\mathrm{C}$
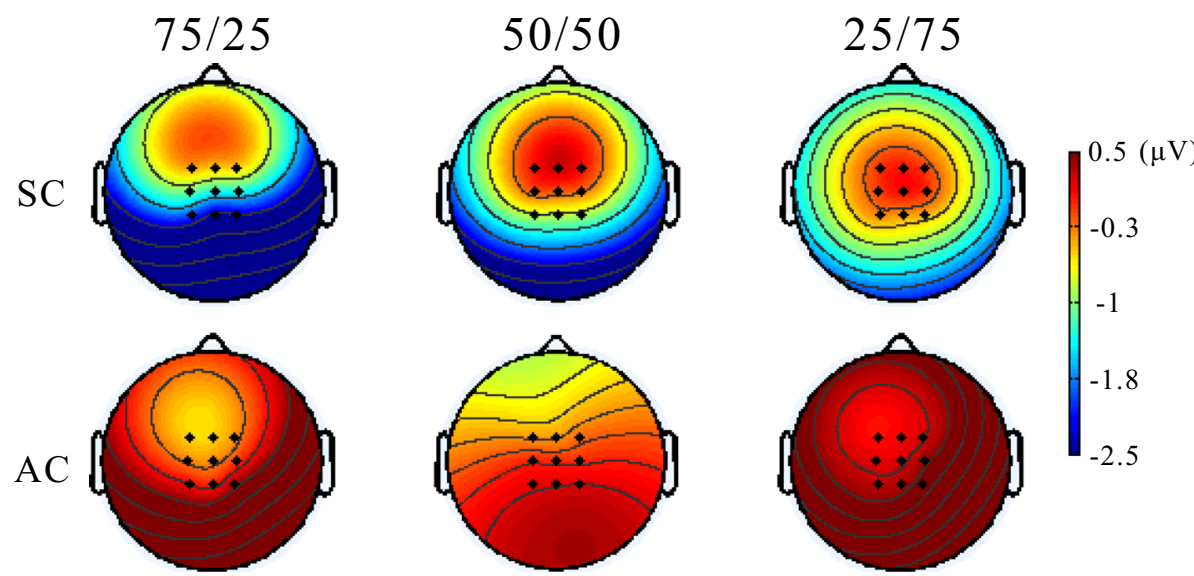

Fig. 3 The results of $\mathrm{N} 2$ wave. (a) The average ERP wave at the $\mathrm{Cz}$ electrode. The two perpendicular lines denote the 275-325 time window. (b, left) The average ERP potential of $\mathrm{Cz}$ in 275-325 time window. (b, right) Simon effect (in potential): incongruent minus congruent condition.

(c) The topographical maps of frontocentral area of the Simon effect in the 275-325 time window. $\mathrm{SC}=$ same-color rule; $\mathrm{Con}=$ congruent; $\mathrm{Inc}=$ incongruent; $\mathrm{AC}=$ alternate-color rule. (Color figure online). $*_{p}<.05$. $* * p<.01 . * * * p<.001$ 
significant, $F(2,45)=1.93, p=.157, \mathrm{y}_{\mathrm{p}}{ }^{2}=.079$, showing that the difference between the $\mathrm{SC}$ and $\mathrm{AC}$ rules were similar across groups. To analyze the PC effect in more detail, we compared the Simon effect under each mapping rule across groups. We calculated the congruency effect (incongruent congruent) for each color-mapping rule of each group. The size of the congruency effect under the SC rule was significantly increased by increasing the ratio of congruent trials $(75 / 25$ group: $-1.29 \mu \mathrm{V}), t(30)=4.15, p<.001$, FDR corrected, $d=1.468$, but decreased and even reversed by increasing the ratio of incongruent trials, although it did not reach statistical significance $(25 / 75$ group: $0.09 \mu \mathrm{V}), t(30)=$ $1.11, p=.277, d=.391$, compared to the $50 / 50$ group ($0.14 \mu \mathrm{V})$. The congruency effect in the $75 / 25$ group was significantly larger than that in the $25 / 75$ group, $t(30)=$ $4.61, p<.001$, FDR corrected, $d=1.631$. In contrast, the congruency effect under the AC rule was marginally significantly decreased and even reversed in the $75 / 25$ group ($0.32 \mu \mathrm{V}), t(30)=1.90, p=.068, d=0.670$, compared to that in the $25 / 75$ group $(0.20 \mu \mathrm{V})$. The comparison between the $75 / 25$ or $25 / 75$ groups and the $50 / 50$ group $(-0.04 \mu \mathrm{V})$ did not reach statistical significance $(p>.1)$. In addition, we averaged the data of the nine adjacent frontocentral electrodes including $\mathrm{Cz}$ ( $\mathrm{FC} 1, \mathrm{FCz}, \mathrm{FC} 2, \mathrm{C} 1, \mathrm{Cz}, \mathrm{C} 2, \mathrm{CP} 1, \mathrm{CPz}, \mathrm{CP} 2)$. Qualitatively equivalent results were obtained as the $\mathrm{Cz}$ results (see Fig. 3c).

In summary, the key findings were that the N2 amplitude of $\mathrm{Cz}$ showed a pattern similar to that of the behavioral results. Specifically, the positive Simon effect in the SC rule was reversed in the $25 / 75$ group, but increased in the $75 / 25$ group compared to the 50/50 group. The negative Simon effect in the AC rule was reversed in the $75 / 25$ group, but increased in the $25 / 75$ group compared to the $50 / 50$ group.

\section{P3b wave}

As P3b is a commonly investigated component for the Simon effect (Leuthold, 2011; Leuthold \& Sommer, 1999), we exploratively analyzed the data of P3b (see Fig. 4). We tested the hypothesis that the $\mathrm{P} 3 \mathrm{~b}$ amplitude also may be affected by the PC manipulation. We report the results of a typical electrode for the P3b component, Pz. Note that P3b showed a reverse pattern of the $\mathrm{N} 2$ results, in which longer RTs were associated with smaller amplitude. In the 375-425-ms time window of $\mathrm{Pz}$ (see Fig. 4a), a significant main effect of Color Mapping was observed, $F(1,45)=89.62, p<.001, \eta_{\mathrm{p}}{ }^{2}=.666$. SC mapping trials $(2.67 \mu \mathrm{V})$ induced higher $\mathrm{P} 3 \mathrm{~b}$ amplitude than did AC mapping trials $(1.43 \mu \mathrm{V})$. The main effect of Group was not significant, $F(2,45)=0.19, p=.830, \eta_{\mathrm{p}}{ }^{2}=.008$, indicating that $\mathrm{P} 3 \mathrm{~b}$ amplitude was similar across the three groups. The main effect of Congruency was not significant, either, $F(1,45)=0.09, p=.765, \eta_{p}{ }^{2}=.002$. The three-way interaction of Group $\times$ Color Mapping $\times$ Congruency was not significant, $F(2,45)=1.88, p=.164, \eta_{\mathrm{p}}{ }^{2}=.077$. The interaction between Group and Congruency was significant, $F(2,45)$ $=25.91, p<.001, \eta_{\mathrm{p}}{ }^{2}=.535$, showing that $\mathrm{P} 3 \mathrm{~b}$ amplitude was larger in the congruent condition $(2.36 \mu \mathrm{V})$ than in the incongruent condition $(1.43 \mu \mathrm{V})$ in the $75 / 25$ group, but smaller $(1.61 \mu \mathrm{V}$ vs. $2.42 \mu \mathrm{V})$ in the $25 / 75$ group. In addition, there was no significant interaction between Color Mapping and Congruency, $F(1,45)=0.01, p=.937, \mathrm{y}_{\mathrm{p}}{ }^{2}=.000$. Interaction between Group and Color Mapping was not significant, $F(2,45)=1.15, p=.325, \mathrm{y}_{\mathrm{p}}{ }^{2}=.049$, showing that the difference between the $\mathrm{SC}$ and $\mathrm{AC}$ rules was similar across groups. To analyze the PC effect in more detail, we compared the Simon effect under each mapping rule across groups. The size of the congruency effect under the SC rule was significantly increased by increasing the ratio of congruent trials $(75 /$ 25 group: $-1.23 \mu \mathrm{V}), t(30)=3.19, p=.003$, FDR corrected, $d$ $=1.127$, but decreased and even reversed by increasing the ratio of incongruent trials (25/75 group: $1.15 \mu \mathrm{V}), t(30)=$ $2.19, p=.036$, FDR corrected, $d=.775$, compared to the $50 / 50$ group $(0.14 \mu \mathrm{V})$. The congruency effect in the $75 / 25$ group was significantly larger than that in the 25/75 group, $t(30)=4.16, p<.001$, FDR corrected, $d=1.425$. In contrast, the congruency effect under the AC rule was significantly decreased and even reversed in the $75 / 25$ group $(-0.63 \mu \mathrm{V})$, $t(30)=3.06, p=.005$, FDR corrected, $d=1.083$, compared to that in the $25 / 75$ group $(0.47 \mu \mathrm{V})$. The size of the congruency effect in the $75 / 25$ group significantly differed from that in the $50 / 50$ group $(0.28 \mu \mathrm{V}), t(30)=2.47, p=.019$, FDR corrected, $d=.874$, while the congruency effect between the $25 / 75$ group and the 50/50 group did not reach significance, $t(30)=0.78, p$ $=.443, d=.275$. In addition, qualitatively equivalent results were also obtained when averaging over nine adjacent electrodes (CP1, CPz, CP2, P1, Pz, P2, PO1, POz, PO2; see Fig. 4c) as when considering just $\mathrm{Pz}$.

In summary, the P3b amplitude of Pz also showed a PC effect. The positive Simon effect in the SC rule was reversed in the $25 / 75$ group but increased in the $75 / 25$ group compared to the 50/50 group. The negative Simon effect in the AC rule was reversed in the $75 / 25$ group but increased in the $25 / 75$ group compared to the $50 / 50$ group.

\section{$L R P$}

If the PC-manipulation-strengthened S-R associations predicted responses in a way similar to the LTM S-R associations, LRP should be also affected by the PC manipulation. The ANOVA for LRP (of the incongruent condition) with the factors Group and Color Mapping showed a marginally significant main effect of Group (see Fig. 5a), $F(2,45)=2.67, p=$ $.080, \eta_{\mathrm{p}}{ }^{2}=.062$, showing that the amplitude of LRP in the $75 /$ 25 group $(1.21 \mu \mathrm{V})$ was larger than that in the 50/50 group $(0.86 \mu \mathrm{V})$ and in the $25 / 75$ group $(0.62 \mu \mathrm{V})$. The main effect of Color Mapping was also marginally significant, $F(1,45)=$ 

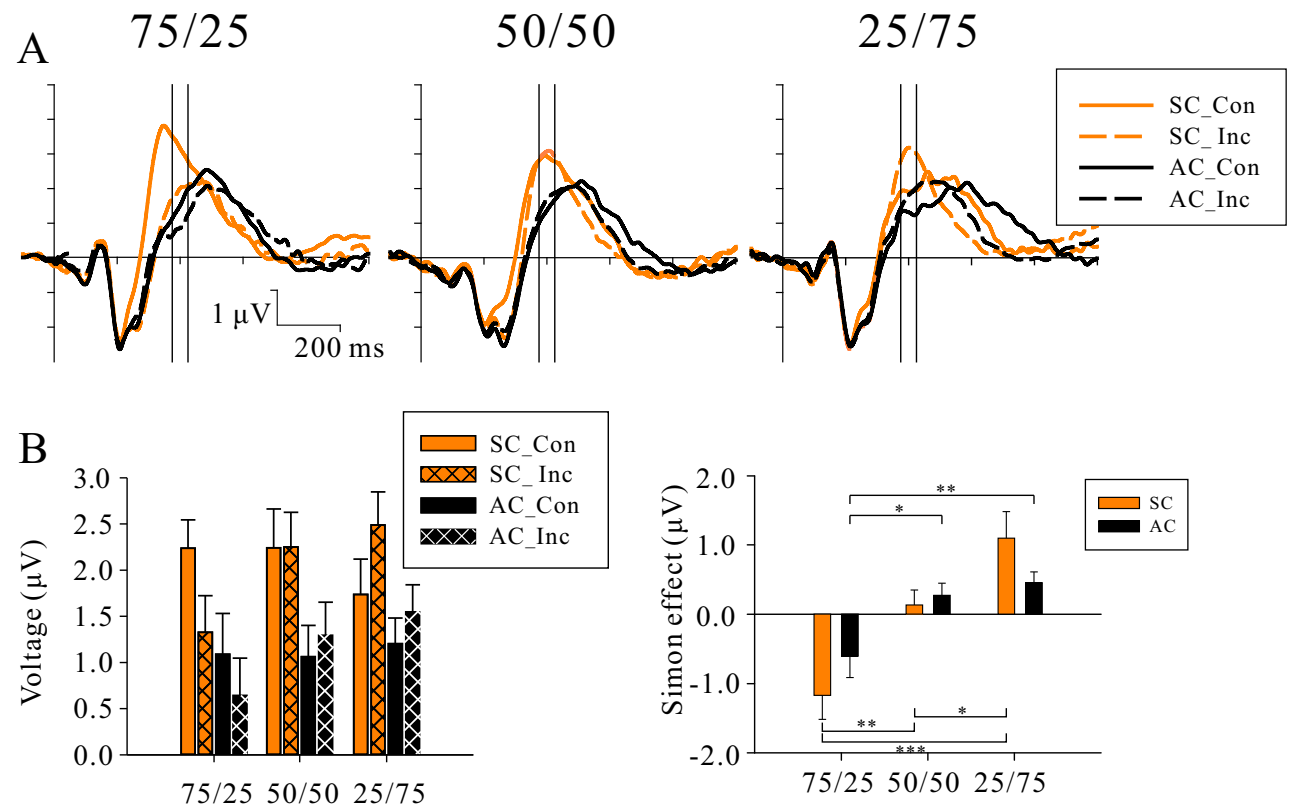

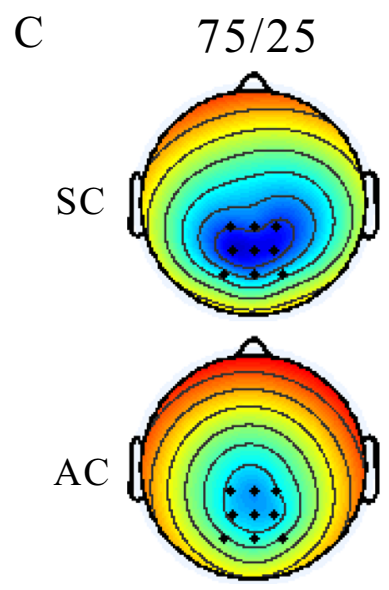

Fig. 4 The results of $\mathrm{P} 3$ component. (a) The average ERP wave at the $\mathrm{Pz}$ electrode. The two perpendicular lines denote the 375-425 time window. (b, left) The average ERP potential of $\mathrm{Pz}$ in 375-425 time window. (b, right) Simon effect (in potential): incongruent minus congruent. (c) The
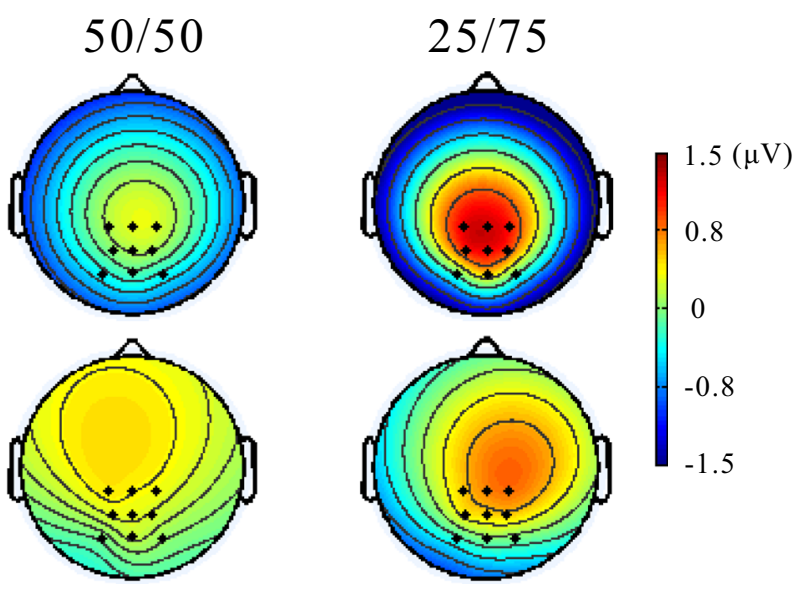

topographical maps of parietal area of the Simon effect in the 375-425 time window. $\mathrm{SC}=$ same-color rule; $\mathrm{Con}=$ congruent; $\mathrm{Inc}=$ incongruent; $\mathrm{AC}=$ alternate-color rule. (Color figure online). $* p<.05 . * * p<.01 . * * * p$ $<.001$
3.98, $p=.052, \eta_{\mathrm{p}}{ }^{2}=.081$, showing that the LRP amplitude was larger in the $\mathrm{SC}(0.96 \mu \mathrm{V})$ than in the AC rule $(0.84 \mu \mathrm{V})$. However, the interaction between Group and Color Mapping was not significant, $F(2,45)=1.48, p=.239, \eta_{\mathrm{p}}{ }^{2}=.062$, indicating that the difference in LRP amplitude between groups did not vary according to color-mapping rules. For the SC rule (see Fig. 5b), independent-samples $t$ test showed that the LRP amplitude was larger in the $75 / 25$ group $(1.24 \mu \mathrm{V})$ than in the $25 / 75$ group $(0.65 \mu \mathrm{V}), t(30)=2.26, p$ $=.031, \mathrm{FDR}$ corrected, $d=.799$. The comparison between the $75 / 25$ or $25 / 75$ group and the $50 / 50$ group $(1.00 \mu \mathrm{V})$ did not reach statistical significance $(p>.1)$. For the AC rule, the LRP amplitude was marginally significantly larger in the 75/25 group $(1.19 \mu \mathrm{V})$ than in the $25 / 75$ group $(0.60 \mu \mathrm{V}), t(30)=$ $1.91, p=.066, d=0.675$. The comparison between the $75 / 25$ or $25 / 75$ group and the $50 / 50$ group $(0.73 \mu \mathrm{V})$ did not reach statistical significance $(p>.1)$. In summary, the LRP amplitude increased in the 75/25 group, but decreased in the 25/75 group, compared to that in the 50/50 group, irrespective of color mapping.

\section{Time-frequency analysis}

In addition to the $\mathrm{N} 2$ component, the theta band activity of frontocentral sites is suggested to be a marker for conflict detection (Cohen \& Ridderinkhof, 2013; Nigbur et al., 2011). Therefore, there should be also a PC effect in the theta band activity, if the PC-manipulation-strengthened S-R associations modulated cognitive control. We report the results of theta band activity at $\mathrm{Cz}$ electrode in $300-600 \mathrm{~ms}$ time 

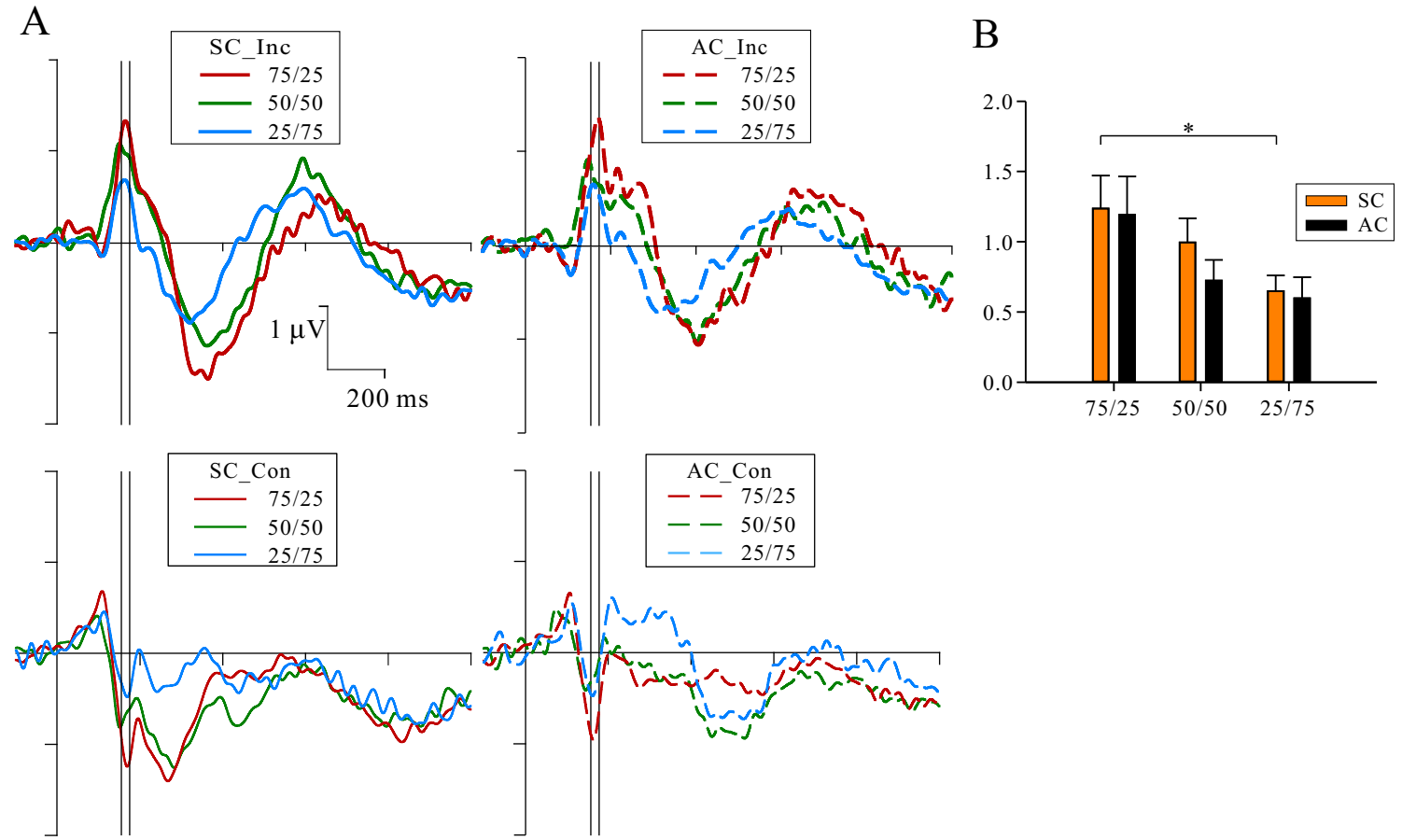

Fig. 5 The results of LRP. (a) The average LRP wave of the four conditions. The two perpendicular lines denote the 150-175 time window. Note that the results of the congruent conditions are also shown here, without further statistical analysis. (b) The average LRP

window (see Fig. 6a). The ANOVA did not reveal a significant main effect of Group, $F(2,45)=0.10, p=.903, \eta_{\mathrm{p}}{ }^{2}=.005$, indicating that theta band power was similar across groups. The main effect of Color Mapping was not significant, $F(1$, $45)=1.10, p=.299, \eta_{\mathrm{p}}{ }^{2}=.024$. The main effect of Congruency was not significant, $F(1,45)=0.77, p=.384$, $\eta_{\mathrm{p}}{ }^{2}=.017$. The three-way interaction of Group $\times$ Color Mapping $\times$ Congruency was not significant, $F(2,45)=1.19$, $p=.314, \eta_{\mathrm{p}}{ }^{2}=.050$. However, the interaction between Group and Congruency was significant, $F(2,45)=30.18, p<.001$, $\eta_{\mathrm{p}}{ }^{2}=.573$, showing that congruent trials $(1.33 \mathrm{~dB})$ elicited weaker theta band power than incongruent trials $(2.30 \mathrm{~dB})$ in the $75 / 25$ group, while congruent trials $(2.08 \mathrm{~dB})$ elicited stronger power than incongruent trials $(1.30 \mathrm{~dB})$ in the $25 /$ 75 group. There was also a significant interaction between Color Mapping and Congruency, $F(1,45)=62.35, p<.001$, $\eta_{\mathrm{p}}{ }^{2}=.581$, indicating that theta band power was weaker in the congruent condition $(1.32 \mathrm{~dB})$ than in the incongruent condition $(2.03 \mathrm{~dB})$ in the $\mathrm{SC}$ rule, while the power was stronger in the congruent condition $(2.03 \mathrm{~dB})$ than in the incongruent condition $(1.48 \mathrm{~dB})$ in the $\mathrm{AC}$ rule. To analyze the $\mathrm{PC}$ effect in more detail, we compared the Simon effect under each mapping rule across groups. The congruency effect under the $\mathrm{SC}$ rule was significantly increased by increasing the ratio of congruent trials $(75 / 25$ group: $1.77 \mathrm{~dB}), t(30)=3.62, p=$ .001 , FDR corrected, $d=1.281$, but reversed in the $25 / 75$ group $(-0.29 \mathrm{~dB}), t(30)=3.75, p<.001$, FDR corrected, $d=$ potential in 150-175 time window of the incongruent trials in the SC and $\mathrm{AC}$ mapping rules. $\mathrm{SC}=$ same-color rule; $\mathrm{Con}=$ congruent; $\mathrm{Inc}=$ incongruent; $\mathrm{AC}=$ alternate-color rule. (Color figure online). ${ }^{*} p<.05$. $* * p<.01 . * * * p<.001$

1.327 , compared to the $50 / 50$ group $(0.65 \mathrm{~dB})$. The congruency effect in the $75 / 25$ group was significantly larger than that in the $25 / 75$ group, $t(30)=6.30, p<.001$, FDR corrected, $d=2.227$. In contrast, the congruency effect under the AC rule was decreased and even reversed in the 75/25 group $(0.18 \mathrm{~dB}), t(30)=2.48, p=.019$, FDR corrected, $d=.876$, but increased in the $25 / 75$ group $(-1.28 \mathrm{~dB}), t(30)=2.67, p=$ .011 , FDR corrected, $d=.946$, compared to the 50/50 group ($0.54 \mathrm{~dB}$ ). The congruency effect in the $75 / 25$ group was significantly smaller than that in the $25 / 75$ group, $t(30)=4.37, p$ $<.001$, FDR corrected, $d=1.544$. In addition, qualitatively equivalent results were also obtained when averaging over nine adjacent frontocentral electrodes as when considering just $\mathrm{Cz}$ (see Fig. 6c), similar to the N2 analyses.

In summary, the novel findings were that the theta band power of $\mathrm{Cz}$ also showed a PC effect, similar to the behavioral and $\mathrm{N} 2$ results. Most importantly, the positive Simon effect in the $\mathrm{SC}$ rule was also reversed in the 25/75 group compared to the 50/50 group, and the negative Simon effect in the AC rule was reversed in the $75 / 25$ group compared to the 50/50 group.

\section{Discussion}

In this study, we manipulated the $\mathrm{PC}$ with the H\&M task. The results of behavior, the N2 component and theta band of frontocentral sites, and LRP together provided a picture that 
a $75 / 25$

$50 / 50$

$25 / 75$
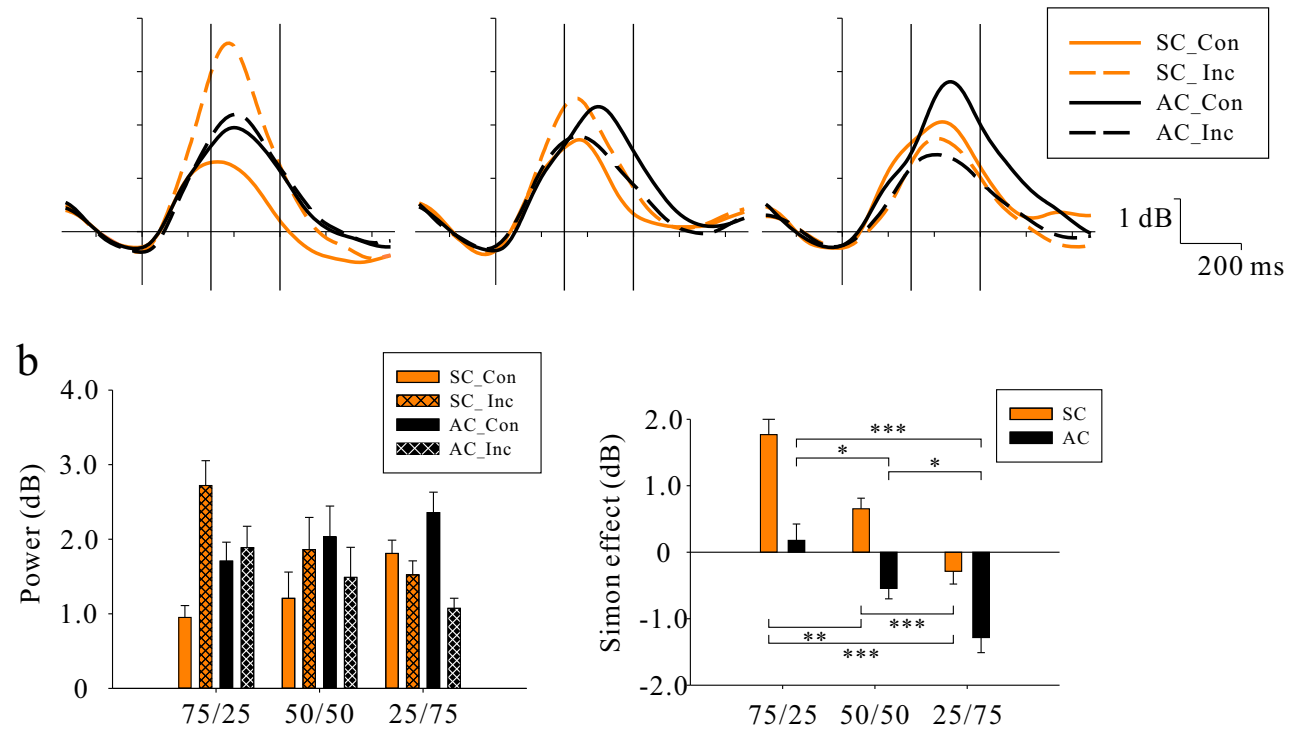

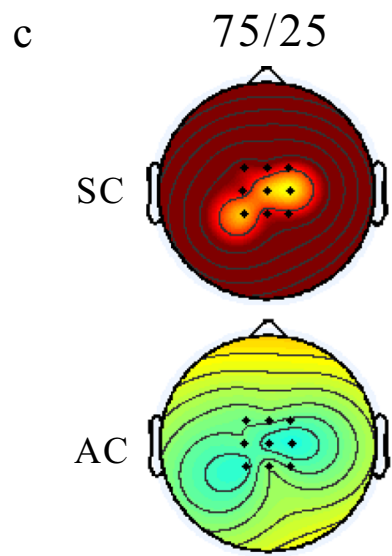

Fig. 6 The results of ERSP. (a) The average ERSP of the theta band at the $\mathrm{Cz}$ electrode. The two perpendicular lines denote the 300-600 time window. (b, left) The average theta band ERSP of Cz in 300-600 time window. (b, right) Simon effect (in power): incongruent minus congruent.
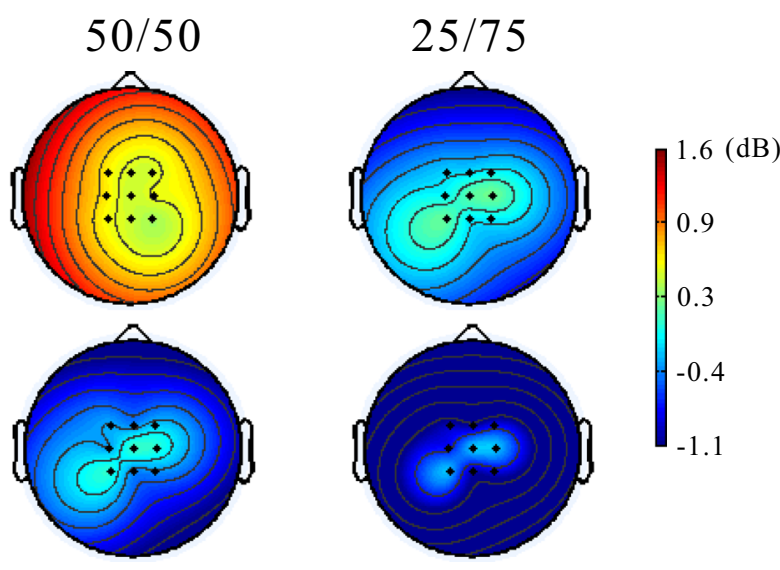

(c) The topographical maps of frontocentral area of the Simon effect in the 300-600 time window. SC = same-color rule; Con = congruent; Inc = incongruent; $\mathrm{AC}=$ alternate-color rule. (Color figure online). ${ }^{*} p<.05$. $* * p<.01 . * * * p<.001$

the PC-manipulation-strengthened S-R associations that modulated cognitive control predicted responses in a way similar to long-term-memory spatial S-R associations. Behavioral results revealed a significant PC effect. Most importantly, the positive Simon effect in the SC rule was reversed by increasing the ratio of incongruent trials, and the negative Simon effect in the AC rule was reversed by increasing the ratio of congruent trials. These results suggest that spatially compatible or incompatible S-R associations were strengthened and used to predict responses. EEG results revealed that the N2 component and the theta band of the time-frequency analysis at frontocentral sites also showed a PC effect. Especially pronounced in the theta band activity, it showed a pattern similar to the behavioral results: the reversal of the positive Simon effect ( $\mathrm{SC}$ rule) by increasing the ratio of incongruent trials and the reversal of the negative Simon effect (AC rule) by increasing ratio of the congruent trials. These suggest that the cognitive control system monitored for the conflict induced by the strengthened irrelevant spatial S-R associations. In addition, the amplitude of the LRP activation reflecting the response predicted by spatially compatible S-R associations was reduced or increased by increasing the ratio of incongruent or congruent trials, suggesting the counteractive or enhancing effect of the strengthened spatially incompatible or compatible S-R associations on LRP activation.

\section{The PC effect and S-R learning}

The behavioral results are consistent with the findings in previous studies (Hommel, 1994; Marble \& Proctor, 2000), showing the reversal of the classic Simon effect by increasing the ratio of incongruent trials. In addition, increasing the ratio 
of congruent trials resulted in the reversal of the negative Simon effect (AC rule). The results also replicate the behavioral findings of one of our recent fMRI studies (Xia et al., 2016), in which the PC of the H\&M task was similarly manipulated. The results suggest that the spatially incompatible or compatible S-R associations are strengthened and used to predict responses. This idea is also in line with the contingency learning account, which was proposed originally for interpreting the item-specific PC effect in the Stroop task (Atalay \& Misirlisoy, 2012; Grandjean et al., 2013; Hazeltine \& Mordkoff, 2014; Schmidt, 2013a, 2013b; Schmidt \& Besner, 2008). The contingency (i.e., correlation) between stimuli and responses may be learned by the brain and used to prepare responses. In other words, the strength of $\mathrm{S}-\mathrm{R}$ associations is modulated. This account fits very well with the behavioral findings of the reversed Simon effect due to PC manipulation. When the responses defined by the relevant S-R associations and those predicted by the PCmanipulation-strengthened irrelevant spatial S-R associations were different, the conflict between them had to be resolved, resulting in longer RT. In contrast, the attention modulation account has difficulty in interpreting the reversal of the conflict effects. Directing more attention to the relevant dimension and/or less to the irrelevant dimension may weaken the influence of the irrelevant dimension and therefore reduce the interference effect, but may not reverse the interference effect. However, although this study suggests that S-R learning may play a critical role in the PC effect, it does not exclude the possibility that attentional control is adjusted due to manipulating the PC. Some studies showed that control can operate at a block level. For example, the transfer effect from PC-biased tasks or items to unbiased tasks or items suggests that global adjustments of attentional control occur (Bugg \& Chanani, 2011; Funes, Lupianez, \& Humphreys, 2010; TorresQuesada, Funes, \& Lupiáñez, 2013). In addition, the ERP results of this study actually suggest that the aMCC monitors for the conflict induced by the strengthened irrelevant spatial S-R associations, implying that S-R learning may modulate cognitive control (see below for further discussion). Note that this is a highly active (and contentious) debate in the literature. Some studies suggest that the PC effects for unbiased items can still be explained from a learning perspective (Schmidt, 2013c, 2014; Schmidt, Lemercier, \& De Houwer, 2014).

\section{N2 and theta oscillation}

It has been suggested that the N2 component at the frontocentral sites, which peaks around $250-350 \mathrm{~ms}$ after stimulus onset, may be an electrophysiological marker for cognitive control (for a review, see Folstein \& Van Petten, 2008). Mostly related to this study, in interference tasks the amplitude of N2 usually increases in high conflict condition relative to low conflict condition (Danielmeier, Wessel,
Steinhauser, \& Ullsperger, 2009; Forster, Carter, Cohen, \& Cho, 2011; van Veen \& Carter, 2002a), reflecting the detection of conflict in cognitive processing (Ridderinkhof, van den Wildenberg, Segalowitz, \& Carter, 2004; Yeung et al., 2004). In addition, the $\mathrm{N} 2$ amplitude may be modulated, showing a similar conflict adaptation or PC effect as in the behavioral results (Clayson \& Larson, 2011; Jiang, van Gaal, Bailey, Chen, \& Zhang, Jiang et al. 2013; Panadero, Castellanos, \& Tudela, 2015), suggesting that the variation in the N2 amplitude may reflect the dynamic of cognitive control. These ERP results mirror the findings of fMRI studies (Blais \& Bunge, 2010; Botvinick, Nystrom, Fissell, Carter, \& Cohen, 1999; Carter et al., 2000). This is consistent with the dipole source location analyses, suggesting that the frontocentral N2 component possibly originates from aMCC activity (van Veen \& Carter, 2002b). In addition to the traditional average approach of ERP, time-frequency analysis has been shown to be a useful tool for ERP studies (Makeig, Debener, Onton, \& Delorme, 2004). Particularly, frontal midline theta band $(4-8 \mathrm{~Hz})$ activity has been implicated in cognitive control processes, such as conflict and error processing (Cavanagh \& Frank, 2014; Cohen, 2014). The power of theta band increases in the incongruent condition compared to the congruent condition in the Simon (Cohen \& Ridderinkhof, 2013; Nigbur et al., 2011; van Driel, Swart, Egner, Ridderinkhof, \& Cohen, 2015; Wang, Li, Zheng, Wang, \& Liu, 2014), Stroop (Hanslmayr et al., 2008; Wang et al., 2014; Zhao et al., 2015), Flanker (Nigbur, Cohen, Ridderinkhof, \& Stürmer, 2012; Nigbur et al., 2011) and response priming (Pastötter, Dreisbach, \& Bäuml, 2013; Pastötter, Hanslmayr, \& Bäuml, 2010) tasks. The theta band power also increases following response errors (Cavanagh, Cohen, \& Allen, 2009; Luu, Tucker, \& Makeig, 2004; Trujillo \& Allen, 2007). These results suggest that increases in the theta band activity might reflect the detection of the need for cognitive control. In addition, the theta band power shows conflict adaptation similar to behavioral results (Cohen \& Ridderinkhof, 2013; Pastötter et al., 2013; van Driel et al., 2015), suggesting that it might underlie the dynamics of cognitive control. Furthermore, the phase synchronization of theta band between medial and lateral frontal regions is enhanced in the incongruent trials (Cohen \& Ridderinkhof, 2013; Hanslmayr et al., 2008; Nigbur et al., 2012; Oehrn et al., 2014) or following response errors. This suggests the communication between brain regions and the engagement of control triggered by medial frontal activity. It has been suggested that the frontocentral theta activity also has an $\mathrm{aMCC} /$ presupplementary motor area generator (for a review, see Cavanagh \& Frank, 2014). This is in line with the similar results of the frontocentral $\mathrm{N} 2$ component and theta band in interference tasks (e.g., Nigbur et al., 2011).

The N2 amplitude was larger in the AC rule than in the SC rule, suggesting more response conflict in the $\mathrm{AC}$ rule. 
Importantly, the PC effect was present in N2 amplitude and theta band activity. Particularly, these two indices also showed the reversal of the positive Simon effect (SC rule) in the 25/75 group and the reversal of the negative Simon effect (AC rule) in the 75/25 group, similar to the behavioral results. These results replicate the findings of one recent fMRI study (Xia et al., 2016), in which the aMCC activity showed a similar reversal pattern with manipulating PC. These neural findings might not fit with a pure contingency learning account, but rather suggest that the cognitive control system monitored for the conflict induced by the strengthened irrelevant spatial S-R associations. This idea is also supported by the results of an ERP study with context PC effect (Panadero et al., 2015). In the mostly incongruent condition, the Stroop-like conflict effect in both RT and N2 amplitude was also reversed (i.e., faster $\mathrm{RT}$ and larger N2 amplitude in the congruent condition), suggesting that the irrelevant word information was used to predict response.

\section{Lateralized readiness potential}

Many studies have shown the initial dip of LRP in the incongruent condition of the Simon task, reflecting the activation of incorrect response evoked by LTM spatially compatible S-R associations (De Jong et al., 1994; Stürmer, Leuthold, Soetens, Schröter, \& Sommer, 2002; ValleInclán, 1996a, 1996b; Valle-Inclán \& Redondo, 1998). The incorrect response activation in LRP is also present when it is response locked (Cespón, Galdo-Álvarez, \& Díaz, 2013a, 2013b; Praamstra \& Plat, 2001). It has been discussed that in the horizontal Simon task, the initial LRP deflection reflecting incorrect response activation could be contaminated with perceptual/attentional processing due to the lateral presentation of stimulus (De Jong et al., 1994; Praamstra, 2007; Praamstra \& Oostenveld, 2003; Valle-Inclán, 1996a). Several studies, therefore, employed the vertical Simon task to avoid this confound (Stürmer et al., 2002; Valle-Inclán, 1996a). In contrast, some studies reported no initial incorrect response activation in the LRP of the vertical Simon task, which was only shown in the horizontal Simon task (Vallesi et al., 2005; Wiegand \& Wascher, 2005). This is possibly because there is no direct visuomotor transformation in the vertical dimension, as suggested by the RT distribution analyses (Wiegand \& Wascher, 2005). In this study, we employed the horizontal H\&M task, not only because the horizontal layout may induce LRP reliably but also because this study concerned the modulation of LRP (not LRP itself). With the manipulation of PC, there was neither need nor beneficial effect with biasing perceptual/attentional processing to a given location, as stimuli were equally distributed in the left and right positions. Therefore, the increase or decrease in the amplitude of LRP observed in this study was unlikely to result from perceptual/attentional processes. The behavioral results suggest that this modulation rather resulted from applying the strengthened irrelevant spatial S-R associations to predict responses. Specifically, the $75 / 25$ and 25/75 groups strengthened spatially compatible and incompatible S-R associations in STM, respectively, and used them to guide responses. These STM S-R associations may either enhance or counteract the effect of the LTM spatial S$\mathrm{R}$ associations on LRP. Our results are consistent with one previous ERP study (Stürmer et al., 2002), showing somewhat increased initial incorrect LRP activity in the high PC condition compared to the low PC condition. One recent fMRI study (Xia et al., 2016) that employed a similar design to this study revealed increased activity in dorsal frontoparietal regions (including dorsal premotor cortex) in both the high and low PC conditions relative to the PC unbiased condition, suggesting that these regions might present the strengthened irrelevant S-R associations.

\section{P3b component}

The P3b component, which peaks at parietal sites $300 \mathrm{~ms}$ or later after task-relevant stimulus onset, has been traditionally implicated in "context updating" (Donchin \& Coles, 1998; Polich, 2007), reflecting stimulus evaluation time. However, the view that P3b latency reflects the duration of perceptual processing has been challenged (for a review, see Verleger, 1997), for example, by the ERP studies with the Simon task (Leuthold, 2011; Leuthold \& Sommer, 1999). In these studies, the Simon effect is also present in the P $3 b$ latency: longer latency in the incongruent condition than in the congruent condition. These results suggest that P3b latency also reflects the time of response-related processing, as the Simon effect is attributed to the conflict in response selection (Hommel, 2011). In addition to the latency, the amplitude of the $\mathrm{P} 3 \mathrm{~b}$ component may be modulated by the Simon effect, showing reduced amplitude in the incongruent condition compared to the congruent condition (Cespón et al., 2013b; Galashan, Wittfoth, Fehr, \& Herrmann, 2008; Leuthold \& Schröter, 2006; Valle-Inclán, 1996a, 1996b). In other words, a more difficult condition with longer RTs is associated with lower P3b amplitude. Consistent with these previous studies, P3b amplitude also showed a color-mapping effect and the PC effect in this study. The difficult conditions were also associated with reduced P3b amplitude. These results are particularly consistent with an ERP study also using the Hedge and Marsh task, showing reduced P3b amplitude in the SC than in the AC mapping (Valle-Inclán, 1996b). It has been shown that $\mathrm{P} 3 \mathrm{~b}$ amplitude may be modulated by "subjective probability" (expectancy) or attention (Donchin \& Coles, 1998). Increasing the probability of a target in the oddball task results in decreased P3b amplitude (Duncan-Johnson \& Donchin, 1977), suggesting less context updating in working memory. In contrast, the present results showed that 
conditions with high frequency in the PC-manipulated groups were associated with increased $\mathrm{P} 3 \mathrm{~b}$ amplitude, which is in conflict with the "subjective probability" view. These results rather suggest that $\mathrm{P} 3 \mathrm{~b}$ amplitude might also reflect the extent of simplicity of the transformation from stimuli to responses (Verleger, Jaskowski, \& Wascher, 2005). The easier the transformation, the higher the $\mathrm{P} 3 \mathrm{~b}$ amplitude. This idea is also supported by the reduced amplitude in AC mapping in this study and in the incompatible condition of the Simon task (see above), which are the difficult conditions requiring more complicated S-R transformation.

\section{Conclusion}

The reversals of the positive and negative Simon effects in RT due to manipulating PC suggest that task-irrelevant spatial S$\mathrm{R}$ associations were strengthened and used to predict responses. The reversals of the interference effects in N2 amplitude and theta band activity suggest that the strengthened STM spatial S-R associations could modulate cognitive control system, which monitored for the conflict induced by the task-irrelevant spatial S-R associations. Finally, the PC manipulation induced increases or decreases in LRP amplitude suggest that the strengthened STM spatial S-R associations were applied in a way similar to the LTM spatial S-R associations.

Acknowledgements We are grateful to Dr. Ping Huang for technical help with EEG data collection. This work was supported by the National Natural Science Foundation of China (Grant 31271085 to L.W.; Grant 31470978 to Z.Y.), a South China Normal University Research Start-Up Grant to L.W. Conflict of Interest: No.

\section{References}

Abrahamse, E. L., Duthoo, W., Notebaert, W., \& Risko, E. F. (2013). Attention modulation by proportion congruency: The asymmetrical list shifting effect. Journal of Experimental Psychology: Learning, Memory, and Cognition, 39(5), 1552-1562.

Atalay, N. B., \& Misirlisoy, M. (2012). Can contingency learning alone account for item-specific control? Evidence from within- and between-language ISPC effects. Journal of Experimental Psychology: Learning, Memory, and Cognition, 38(6), 1578-1590.

Benjamini, Y., Krieger, A. M., \& Yekutieli, D. (2006). Adaptive linear step-up procedures that control the false discovery rate. Biometrika, 93, 491-507.

Blais, C., \& Bunge, S. (2010). Behavioral and neural Evidence for itemspecific performance monitoring. Journal of Cognitive Neuroscience, 22(12), 2758-2767.

Blais, C., Robidoux, S., Risko, E. F., \& Besner, D. (2007). Item-specific adaptation and the conflict-monitoring hypothesis: A computational model. Psychological Review, 114(4), 1076-1086.

Botvinick, M. M., Braver, T. S., Barch, D. M., Carter, C. S., \& Cohen, J. D. (2001). Conflict monitoring and cognitive control. Psychological Review, 108(3), 624-652.
Botvinick, M. M., Nystrom, L. E., Fissell, K., Carter, C. S., \& Cohen, J. D. (1999). Conflict monitoring versus selection-for-action in anterior cingulate cortex. Nature, 402(6758), 179-181.

Bugg, J. M., \& Chanani, S. (2011). List-wide control is not entirely elusive: Evidence from picture-word Stroop. Psychonomic Bulletin \& Review, 18(5), 930-936.

Bugg, J. M., \& Crump, M. J. (2012). In support of a distinction between voluntary and stimulus-driven dontrol: A review of the literature on proportion congruent effects. Frontiers in Psychology, 3, 367.

Carter, C. S., Macdonald, A. M., Botvinick, M., Ross, L. L., Stenger, V. A., Noll, D., \& Cohen, J. D. (2000). Parsing executive processes: Strategic vs. evaluative functions of the anterior cingulate cortex. Proceedings of the National Academy of Sciences of the United States of America, 97(4), 1944-1948.

Cavanagh, J. F., Cohen, M. X., \& Allen, J. J. (2009). Prelude to and resolution of an error: EEG phase synchrony reveals cognitive control dynamics during action monitoring. Journal of Neuroscience, 29(1), 98-105.

Cavanagh, J. F., \& Frank, M. J. (2014). Frontal theta as a mechanism for cognitive control. Trends in Cognitive Sciences, 18(8), 414-421.

Cespón, J., Galdo-Álvarez, S., \& Díaz, F. (2013a). Age-related changes in ERP correlates of visuospatial and motor processes. Psychophysiology, 50(8), 743-757.

Cespón, J., Galdo-Álvarez, S., \& Díaz, F. (2013b). Similarities and differences between interference from stimulus position and from direction of an arrow: Behavioral and event-related potential measures. International Journal of Psychophysiology, 90(2), 180-189.

Clayson, P. E., \& Larson, M. J. (2011). Effects of repetition priming on electrophysiological and behavioral indices of conflict adaptation and cognitive control. Psychophysiology, 48(12), 1621-1630.

Cohen, M. X. (2014). A neural microcircuit for cognitive conflict detection and signaling. Trends in Neurosciences, 37(9), 480-490.

Cohen, M. X., \& Ridderinkhof, K. R. (2013). EEG source reconstruction reveals frontal-parietal dynamics of spatial conflict processing. PLoS One, 8(2), e57293.

Coles, M. G. (1989). Modern mind-brain reading: Psychophysiology, physiology, and cognition. Psychophysiology, 26(3), 251-269.

Crump, M. J., Gong, Z., \& Milliken, B. (2006). The context-specific proportion congruent Stroop effect: Location as a contextual cue. Psychonomic Bulletin \& Review, 13(2), 316-321.

Crump, M. J., \& Milliken, B. (2009). The flexibility of context-specific control: Evidence for context-driven generalization of item-specific control settings. The Quarterly Journal of Experimental Psychology, 62(8), 1523-1532.

Danielmeier, C., Wessel, J. R., Steinhauser, M., \& Ullsperger, M. (2009). Modulation of the error-related negativity by response conflict. Psychophysiology, 46(6), 1288-1298.

De Jong, R., Liang, C., \& Lauber, E. (1994). Conditional and unconditional automaticity: A dual-process model of effects of spatial stimulus-response correspondence. Journal of Experimental Psychology: Human Perception and Performance, 20(4), 731-750.

De Jong, R., Wierda, M., Mulder, G., \& Mulder, L. (1988). Use of partial stimulus information in response processing. Journal of Experimental Psychology: Human Perception and Performance, 14(4), 689-692.

Donchin, E., \& Coles, M. G. H. (1998). Context updating and the P300. Behavioral and Brain Sciences, 21(1), 152-154.

Duncan-Johnson, C. C., \& Donchin, E. (1977). On quantifying surprise: The variation of event-related potentials with subjective probability. Psychophysiology, 14(5), 456-467.

Egner, T., \& Hirsch, J. (2005). Cognitive control mechanisms resolve conflict through cortical amplification of task-relevant information. Nature Neuroscience, 8(12), 1784-1790.

Eriksen, B. A., \& Eriksen, C. W. (1974). Effects of noise letters upon the identification of a target letter in a nonsearch task. Perception \& Psychophysics, 16(1), 143-149. 
Folstein, J. R., \& Van Petten, C. (2008). Influence of cognitive control and mismatch on the N2 component of the ERP: A review. Psychophysiology, 45(1), 152-170.

Forster, S. E., Carter, C. S., Cohen, J. D., \& Cho, R. Y. (2011). Parametric manipulation of the conflict signal and control-state adaptation. Journal of Cognitive Neuroscience, 23(4), 923-935.

Funes, M. J., Lupianez, J., \& Humphreys, G. (2010). Sustained vs. transient cognitive control: Evidence of a behavioral dissociation. Cognition, 114(3), 338-347.

Galashan, D., Wittfoth, M., Fehr, T., \& Herrmann, M. (2008). Two Simon tasks with different sources of conflict: An ERP study of motionand location-based compatibility effects. Biological Psychology, $78(3), 246-252$.

Grandjean, J., D'Ostilio, K., Fias, W., Phillips, C. , Balteau, E. , Degueldre, C. , . . . Collette, F. (2013). Exploration of the mechanisms underlying the ISPC effect: Evidence from behavioral and neuroimaging data. Neuropsychologia, 51(6), 1040-1049.

Gratton, G., Coles, M. G., Sirevaag, E. J., Eriksen, C. W., \& Donchin, E. (1988). Pre- and poststimulus activation of response channels: A psychophysiological analysis. Journal of Experimental Psychology: Human Perception and Performance, 14(3), 331-344.

Groppe, D. M., Urbach, T. P., \& Kutas, M. (2011). Mass univariate analysis of event-related brain potentials/fields: I. A critical tutorial review. Psychophysiology, 48(12), 1711-1725.

Hanslmayr, S., Pastotter, B., Bauml, K. H., Gruber, S., Wimber, M., \& Klimesch, W. (2008). The electrophysiological dynamics of interference during the Stroop task. Journal of Cognitive Neuroscience, $20(2), 215-225$.

Hazeltine, E., \& Mordkoff, J. T. (2014). Resolved but not forgotten: Stroop conflict dredges up the past. Frontiers in Psychology, 5, 1327.

Hedge, A., \& Marsh, N. W. (1975). The effect of irrelevant spatial correspondences on two-choice response-time. Acta Psychologica, 39(6), 427-439.

Hommel, B. (1994). Spontaneous decay of response-code activation. Psychological Research, 56(4), 261-268.

Hommel, B. (2011). The Simon effect as tool and heuristic. Acta Psychologica, 136(2), 189-202.

Jacoby, L. L., Lindsay, D. S., \& Hessels, S. (2003). Item-specific control of automatic processes: Stroop process dissociations. Psychonomic Bulletin \& Review, 10(3), 638-644.

Jiang, J., van Gaal, S., Bailey, K., Chen, A., \& Zhang, Q. (2013). Electrophysiological correlates of block-wise strategic adaptations to consciously and unconsciously triggered conflict. Neuropsychologia, 51(13), 2791-2798.

King, J. A., Korb, F. M., \& Egner, T. (2012). Priming of control: Implicit contextual cuing of top-down attentional set. Journal of Neuroscience, 32(24), 8192-8200.

Leuthold, H. (2011). The Simon effect in cognitive electrophysiology: A short review. Acta Psychologica, 136(2), 203-211.

Leuthold, H., \& Schröter, H. (2006). Electrophysiological evidence for response priming and conflict regulation in the auditory Simon task. Brain Research, 1097(1), 167-180.

Leuthold, H., \& Sommer, W. (1999). ERP correlates of error processing in spatial S-R compatibility tasks. Clinical Neurophysiology, 110(2), $342-357$.

Li, H., Xia, T., \& Wang, L. (2015). Neural correlates of the reverse Simon effect in the Hedge and Marsh task. Neuropsychologia, 75, 119 131.

Lu, C. H., \& Proctor, R. W. (1994). Processing of an irrelevant location dimension as a function of the relevant stimulus dimension. Journal of Experimental Psychology: Human Perception and Performance, 20(2), 286-298.

Luu, P., Tucker, D. M., \& Makeig, S. (2004). Frontal midline theta and the error-related negativity: Neurophysiological mechanisms of action regulation. Clinical Neurophysiology, 115(8), 1821-1835.
MacLeod, C. M. (1991). Half a century of research on the Stroop effect: An integrative review. Psychological Bulletin, 109(2), 163-203.

Makeig, S., Debener, S., Onton, J., \& Delorme, A. (2004). Mining eventrelated brain dynamics. Trends in Cognitive Sciences, 8(5), 204 210 .

Marble, J. G., \& Proctor, R. W. (2000). Mixing location-relevant and location-irrelevant choice-reaction tasks: Influences of location mapping on the Simon effect. Journal of Experimental Psychology: Human Perception and Performance, 26(5), 15151533.

Nigbur, R., Cohen, M. X., Ridderinkhof, K. R., \& Stürmer, B. (2012). Theta dynamics reveal domain-specific control over stimulus and response conflict. Journal of Cognitive Neuroscience, 24(5), 12641274.

Nigbur, R., Ivanova, G., \& Stürmer, B. (2011). Theta power as a marker for cognitive interference. Clinical Neurophysiology, 122(11), 2185-2194.

Oehrn, C. R., Hanslmayr, S., Fell, J., Deuker, L., Kremers, N. A., Do Lam, A. T., .. . Axmacher, N. (2014). Neural communication patterns underlying conflict detection, resolution, and adaptation. Journal of Neuroscience, 34(31), 10438-10452.

Oldfield, R. C. (1971). The assessment and analysis of handedness: The Edinburgh inventory. Neuropsychologia, 9(1), 97-113.

Panadero, A., Castellanos, M. C., \& Tudela, P. (2015). Unconscious context-specific proportion congruency effect in a Stroop-like task. Consciousness and Cognition, 31, 35-45.

Pastötter, B., Dreisbach, G., \& Bäuml, K. H. (2013). Dynamic adjustments of cognitive control: Oscillatory correlates of the conflict adaptation effect. Journal of Cognitive Neuroscience, 25(12), $2167-2178$.

Pastötter, B., Hanslmayr, S., \& Bäuml, K. H. (2010). Conflict processing in the anterior cingulate cortex constrains response priming. NeuroImage, 50(4), 1599-1605.

Polich, J. (2007). Updating P300: An integrative theory of P3a and P3b. Clinical Neurophysiology, 118(10), 2128-2148.

Praamstra, P. (2007). Do's and don'ts with lateralized event-related brain potentials. Journal of Experimental Psychology: Human Perception and Performance, 33(2), 497-502.

Praamstra, P., \& Oostenveld, R. (2003). Attention and movement-related motor cortex activation: A high-density EEG study of spatial stimulus-response compatibility. Cognitive Brain Research, 16(3), 309-322.

Praamstra, P., \& Plat, F. M. (2001). Failed suppression of direct visuomotor activation in Parkinson's disease. Journal of Cognitive Neuroscience, 13(1), 31-43.

Proctor, R. W., \& Pick, D. F. (2003). Display-control arrangement correspondence and logical recoding in the Hedge and Marsh reversal of the Simon effect. Acta Psychologica, 112(3), 259-278.

Ridderinkhof, K. R., van den Wildenberg, W. P., Segalowitz, S. J., \& Carter, C. S. (2004). Neurocognitive mechanisms of cognitive control: The role of prefrontal cortex in action selection, response inhibition, performance monitoring, and reward-based learning. Brain Cognition, 56(2), 129-140.

Schmidt, J. R. (2013a). The parallel episodic processing (PEP) model: Dissociating contingency and conflict adaptation in the item-specific proportion congruent paradigm. Acta Psychologica, 142, 119-126.

Schmidt, J. R. (2013b). Questioning conflict adaptation: Proportion congruent and Gratton effects reconsidered. Psychonomic Bulletin \& Review, 20(4), 615-630.

Schmidt, J. R. (2013c). Temporal learning and list-level proportion congruency: Conflict adaptation or learning when to respond? PLoS One, 8(11), e82320.

Schmidt, J. R. (2014). List-level transfer effects in temporal learning: Further complications for the list-level proportion congruent effect. Journal of Cognitive Psychology, 26(4), 373-385. 
Schmidt, J. R., \& Besner, D. (2008). The Stroop effect: Why proportion congruent has nothing to do with congruency and everything to do with contingency. Journal of Experimental Psychology: Learning, Memory, and Cognition, 34(3), 514-523.

Schmidt, J. R., Lemercier, C., \& De Houwer, J. (2014). Context-specific temporal learning with non-conflict stimuli: Proof-of-principle for a learning account of context-specific proportion congruent effects. Frontiers in Psychology, 5, 1241.

Simon, J. R. (1969). Reactions toward the source of stimulation. Journal of Experimental Psychology, 81(1), 174-176.

Simon, J. R., Sly, P. E., \& Vilapakkam, S. (1981). Effect of compatibility of S-R mapping on reactions toward the stimulus source. Acta Psychologica, 47(1), 63-81.

Stroop, J. R. (1935). Studies of interference in serial verbal reactions. Journal of Experimental Psychology, 18, 643-662.

Stürmer, B., Leuthold, H., Soetens, E., Schröter, H., \& Sommer, W. (2002). Control over location-based response activation in the Simon task: Behavioral and electrophysiological evidence. Journal of Experimental Psychology: Human Perception and Performance, 28(6), 1345-1363.

Torres-Quesada, M., Funes, M. J., \& Lupiáñez, J. (2013). Dissociating proportion congruent and conflict adaptation effects in a SimonStroop procedure. Acta Psychologica, 142(2), 203-210.

Toth, J. P., Levine, B., Stuss, D. T., Oh, A., Winocur, G., \& Meiran, N. (1995). Dissociation of processes underlying spatial s-r compatibility: Evidence for the independent influence of what and where. Consciousness and Cognition, 4(4), 483-501.

Trujillo, L. T., \& Allen, J. J. B. (2007). Theta EEG dynamics of the errorrelated negativity. Clinical Neurophysiology, 118(3), 645-668.

Valle-Inclán, F. (1996a). The locus of interference in the Simon effect: An ERP study. Biological Psychology, 43(2), 147-162.

Valle-Inclán, F. (1996b). The Simon effect and its reversal studied with event-related potentials. International Journal of Psychophysiology, 23(1/2), 41-53.

Valle-Inclán, F., \& Redondo, M. (1998). On the automaticity of ipsilateral response activation in the Simon effect. Psychophysiology, 35(4), 366-371.

Vallesi, A., Mapelli, D., Schiff, S., Amodio, P., \& Umiltà, C. (2005). Horizontal and vertical Simon effect: Different underlying mechanisms? Cognition, 96(1), B33-B43.

van Driel, J., Swart, J. C., Egner, T., Ridderinkhof, K. R., \& Cohen, M. X. (2015). (No) time for control: Frontal theta dynamics reveal the cost of temporally guided conflict anticipation. Cognitive, Affective, \& Behavioral Neuroscience, 15(4), 787-807.

van Veen, V., \& Carter, C. S. (2002a). The timing of action-monitoring processes in the anterior cingulate cortex. Journal of Cognitive Neuroscience, 14(4), 593-602.

van Veen, V., \& Carter, C. S. (2002b). The anterior cingulate as a conflict monitor: FMRI and ERP studies. Physiology \& Behavior, 77(4/5), 477-482.

Verguts, T., \& Notebaert, W. (2008). Hebbian learning of cognitive control: Dealing with specific and nonspecific adaptation. Psychological Review, 115(2), 518-525.

Verguts, T., \& Notebaert, W. (2009). Adaptation by binding: A learning account of cognitive control. Trends in Cognitive Sciences, 13(6), 252-257.

Verleger, R. (1997). On the utility of P3 latency as an index of mental chronometry. Psychophysiology, 34(2), 131-156.

Verleger, R., Jaskowski, P., \& Wascher, E. (2005). Evidence for an integrative role of $\mathrm{P} 3 \mathrm{~b}$ in linking reaction to perception. Journal of Psychophysiology, 19(3), 165-181.

Wang, K., Li, Q., Zheng, Y., Wang, H., \& Liu, X. (2014). Temporal and spectral profiles of stimulus-stimulus and stimulus-response conflict processing. Neurolmage, 89, 280-288.

Wiegand, K., \& Wascher, E. (2005). Dynamic aspects of stimulusresponse correspondence: Evidence for two mechanisms involved in the Simon effect. Journal of Experimental Psychology: Human Perception and Performance, 31(3), 453-464.

Wühr, P., \& Biebl, R. (2009). Logical recoding of S-R rules can reverse the effects of spatial S-R correspondence. Attention, Perception, \& Psychophysics, 71(2), 248-257.

Xia, T., Li, H., \& Wang, L. (2016). Implicitly strengthened task-irrelevant stimulus-response associations modulate cognitive control: Evidence from an fMRI study. Human Brain Mapping, 37(2), 756-772.

Yeung, N., Botvinick, M. M., \& Cohen, J. D. (2004). The neural basis of error detection: Conflict monitoring and the error-related negativity. Psychological Review, 111(4), 931-959.

Zhao, J., Liang, W. K., Juan, C. H., Wang, L., Wang, S., \& Zhu, Z. (2015). Dissociated stimulus and response conflict effect in the Stroop task: Evidence from evoked brain potentials and brain oscillations. Biological Psychology, 104, 130-138. 